Aus der Klinik für Neurochirurgie

(Prof. Dr. med. V. Rohde)

der Medizinischen Fakultät der Universität Göttingen

\title{
Die Bedeutung der Hedgehog-Signalkaskade in der \\ Tumorgenese von spinalen und kraniellen Chordomen
}

\author{
INAUGURAL-DISSERTATION \\ zur Erlangung des Doktorgrades \\ für Zahnheilkunde \\ der Medizinischen Fakultät der \\ Georg-August-Universität zu Göttingen \\ vorgelegt von \\ Amanda Angelika Klemer-Harcej \\ aus \\ Hannover
}

Göttingen 2016 
Dekan:

Referent:

Ko-Referentin:

Drittreferentin:

Datum der mündlichen Prüfung:
Prof. Dr. rer. nat. H. K. Kroemer

Prof. Dr. med. V. Rohde

PD Dr. Imke Metz

PD Dr. Anja Uhmann 
Hiermit erkläre ich, die Dissertation mit dem Titel "Die Bedeutung der HedgehogSignalkaskade in der Tumorgenese von spinalen und kraniellen Chordomen" eigenständig angefertigt und keine anderen als die von mir angegebenen Quellen und Hilfsmittel verwendet zu haben.

Göttingen, den

(Unterschrift) 


\section{Inhaltsverzeichnis}

Abbildungsverzeichnis .11

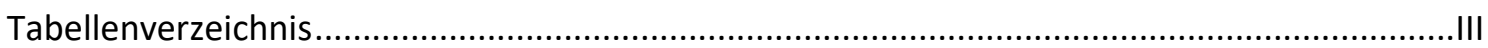

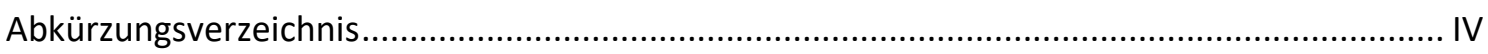

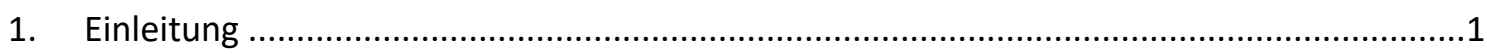

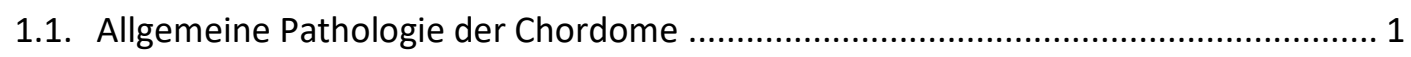

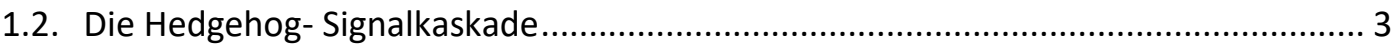

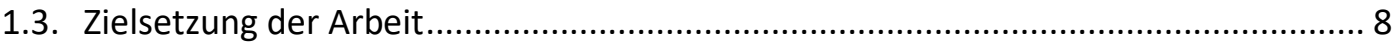

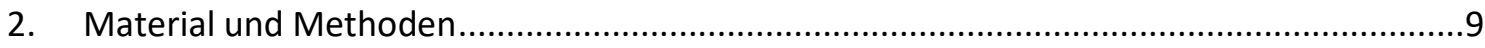

2.1. Patientenkollektiv und Gewebematerialien ........................................................... 9

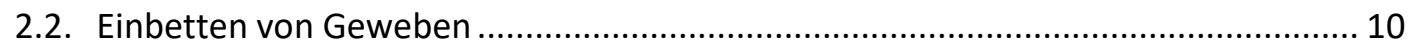

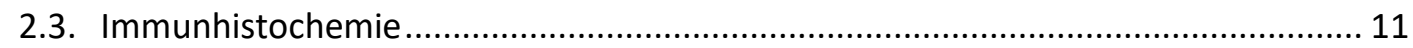

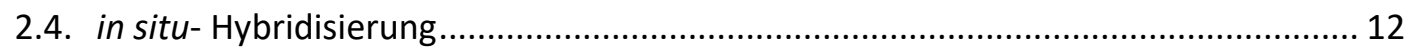

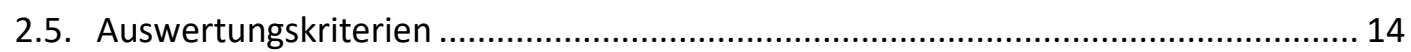

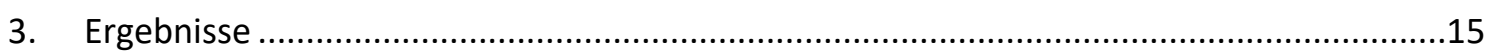

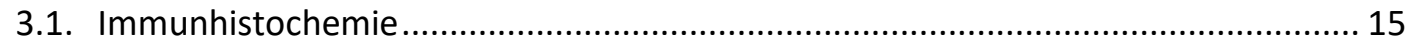

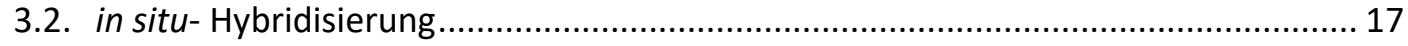

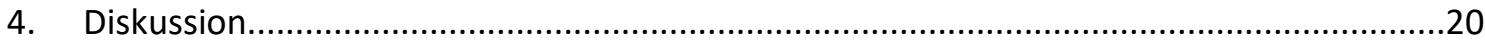

4.1. Mögliche Bedeutung der Shh-Signalkaskade bei der Entstehung von kraniellen und

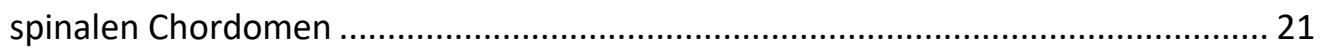

4.2. Einsatz von $H h$ - Signalweg- Inhibitoren in der Tumortherapie ................................ 23

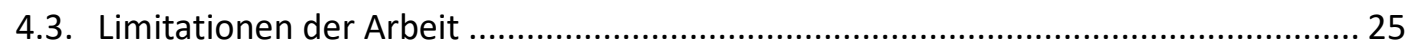

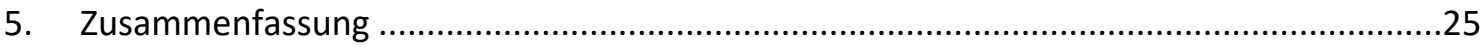

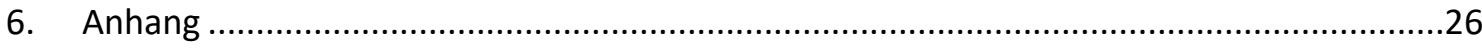

6.1. Patientenkollektiv und Tumormaterialübersicht .................................................. 26

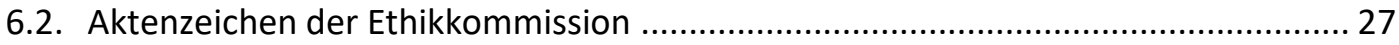

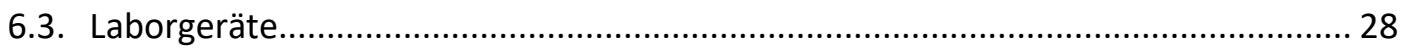

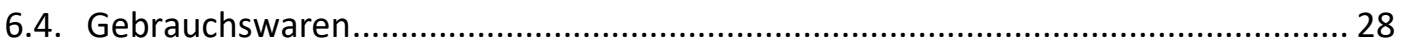

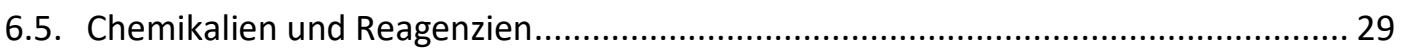

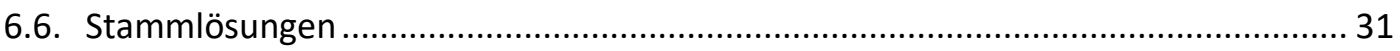

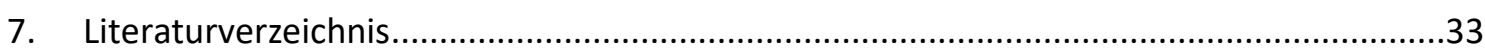


Abbildung 1: Die HE- Färbung eines kraniellen Chordomes zeigt die typischen lappenförmig angeordneten, physaliformen Zellen mit randständigen kleinen Zellkernen (Siegelringzellen) und interzellulärer Schleimhautbildung.

Abbildung 2: Shh- Signalkaskade in der „inaktiven“ Form (modifiziert nach Justilien und Fields 2015, S. 507).

Abbildung 3: Shh-Signalkaskade in der „aktiven“ Form (modifiziert nach Justilien und Fields 2015, S. 507) 6

Abbildung 4: Gegenseitige Wechselbeziehungen innerhalb der Shh-Signalkaskade.... 7

Abbildung 5: Immunhistochemische Färbung der Gli1- Expression bei einem spinalen Chordom 16

Abbildung 6: Immunhistochemische Färbung der Gli1- Expression bei einem kraniellen Chordom.

Abbildung 7: Gegenüberstellung einer kraniellen Chordomprobe von einem Patienten nach positiver in situ- Hybridisierung (Ptch1 (+), Gli1 (+)) und immunhistochemischer Färbung (Shh (+) und Gli1 (+)) im Vergleich 19

Abbildung 8: Schlüsselpositionen der Hh- Signalkaskade-Inhibitoren (modifiziert nach Justilien und Fields 2015, S. 507). 24 
Tabelle 1: $\quad$ Fehlregulationen der Shh-Signalkaskade, die zur Neubildung einer Neoplasie führen (modifiziert nach Hooper und Scott 2005, S. 306)..... 8

Tabelle 2: $\quad$ Übersicht des Patientenkollektivs $(n=20)$

Tabelle 3: $\quad$ Verdünnung der Primär- und Sekundärantikörper für die Immunhistochemie

Tabelle 4: $\quad$ Scoring-System nach Rüschoff et al. 2009 für die Immunhistochemie in den Tumorzellen. 14

Tabelle 5: Immunhistochemie: Verteilung und Reaktionsstärke der kraniellen Chordome bei acht Patienten und 14 Proben, unterteilt in sieben Primärtumoren, fünf erste Rezidive und zwei zweite Rezidive.

Tabelle 6: Immunhistochemie: Verteilung und Reaktionsstärke der spinalen Chordome bei sechs Patienten und 18 Proben, unterteilt in zwölf Primärtumoren und sechs erste Rezidive.

Tabelle 7: $\quad$ in situ- Hybridisierung: Reaktion der kraniellen Chordome bei acht Patienten und 14 Proben, unterteilt in sieben Primärtumoren, fünf erste Rezidive und zwei zweite Rezidive.

Tabelle 8: $\quad$ in situ- Hybridisierung: Reaktion der spinalen Chordome bei sechs Patienten und 18 Proben, unterteilt in zwölf Primärtumoren und sechs erste Rezidive.

Tabelle 9: $\quad$ Patientenkollektiv und Tumormaterialübersicht der Patienten mit kraniellen Chordomen $(n=12)$

Tabelle 10: Patientenkollektiv und Tumormaterialübersicht der Patienten mit spinalen Chordomen $(n=8)$

Tabelle 11: Stammlösungen 


\begin{tabular}{|c|c|}
\hline \multicolumn{2}{|c|}{ Abkürzungsverzeichnis } \\
\hline AEC & 2, 3- Amino- 9- Ethylcarbazol \\
\hline AS & Anti- Sense \\
\hline BBR & Böhringer Blocking Reagent \\
\hline $\mathrm{BCIP}$ & 5- Brom- 4- Chlor- 3- Indoxylphosphat \\
\hline $\mathrm{Bcl} 2$ & B- cell lymphoma 2 \\
\hline $\mathrm{CaCl}_{2}$ & Calciumchlorid \\
\hline CCND1/ 2 & Cyclin D1/ D2 \\
\hline $\mathrm{CO}_{2}$ & Kohlenstoffdioxid \\
\hline Dhh & Desert Hedgehog \\
\hline Dig & Digoxigenin \\
\hline DNA & Deoxyribonucleic Acid \\
\hline DMFA & Dimethylformamid \\
\hline DMPC & Dimethylpyrocarbonat \\
\hline ED & Erstdiagnose \\
\hline EGFR & Epidermal Growth Factor Receptor \\
\hline FCS & Fetal Calf Serum \\
\hline $\mathrm{Fu}$ & Fused \\
\hline GANT & Gli Transcription Factor Inhibitor \\
\hline Geschl. & Geschlecht \\
\hline Gli & Glioma- Associated Oncogene Homolog \\
\hline $\mathrm{H}_{2} \mathrm{O}$ & Wasser \\
\hline $\mathrm{H}_{2} \mathrm{O}_{2}$ & Wasserstoffperoxid \\
\hline $\mathrm{HCl}$ & Chlorwasserstoff \\
\hline $\mathrm{HE}$ & Hämatoxylin- Eosin \\
\hline $\mathrm{Hh}$ & Hedgehog \\
\hline $\mathrm{HNa}_{2} \mathrm{O}_{4} \mathrm{P}$ & Dinatriumhydrogenphosphat \\
\hline HPI & Hh Pathway Inhibitors \\
\hline $\mathrm{ICH}$ & Immunhistochemie \\
\hline IGF & Insulin- Like Growth Factors \\
\hline Ihh & Indian Hedgehog \\
\hline
\end{tabular}




\begin{tabular}{|c|c|}
\hline ISH & In situ- Hybridisierung \\
\hline J. & Jahre \\
\hline Kif 7 & Kinesin- family member 7 \\
\hline 1 & Liter \\
\hline $\mathrm{m}$ & männlich \\
\hline M & Molar \\
\hline $\mathrm{MgCl}_{2}$ & Magnesiumchlorid \\
\hline$\mu$ & mikro \\
\hline $\mathrm{NaCl}$ & Natriumchlorid \\
\hline $\mathrm{NaH}_{2} \mathrm{PO}_{4}$ & Natriumdihydrogenphosphat \\
\hline NBT & Nitro- Blue Tetrazolium Chloride \\
\hline Nr. & Nummer \\
\hline NTM & Natriumchlorid- Tris- Magnesiumchlorid \\
\hline mTOR & mechanistic Target Of Rapamycin \\
\hline $\mathrm{OP}$ & Operation \\
\hline Pat. & Patient \\
\hline PBS & Phosphate Buffered Saline \\
\hline PFA & Paraformaldehyd \\
\hline $\mathrm{PI} 3 \mathrm{~K}$ & Phosphoinositid- 3- Kinase \\
\hline PM & Primärtumor \\
\hline Ptch & Patched \\
\hline RAS & Rat Sarcoma Proto- Onkogen \\
\hline Rez. & Rezidiv \\
\hline RNA & Ribonucleic Acid \\
\hline RNase & Ribonuklease \\
\hline RU-SKI & 2-[(2-Methylbutyl)amino]-1-\{4-[(3-methylphenoxy)methyl]- \\
\hline & 6,7-dihydrothieno[3,2-c]pyridin-5(4H)-yl\}ethanon \\
\hline S & ( \\
\hline SDS & Natriumdodecylsulfat \\
\hline Shh & Sonic hedgehog \\
\hline Ski/ HHAT & Skinny Hh/ Hh Acyltransferase \\
\hline Smo & Smoothened \\
\hline
\end{tabular}


SSC

SuFu

TBS

TGF $\beta$

TR

TRIS

VEGF

w

Wnt
Standard Saline Citrate

Suppressor of Fused

Tris- gepufferte Salzlösung

Transforming Growth Factor beta

Teilresektion

Tris (hydroxymethyl)- aminomethan

Vascular Endothelial Growth Factor

weiblich

Wingless 


\section{Einleitung}

\subsection{Allgemeine Pathologie der Chordome}

Chordome sind seltene, langsam wachsende und maligne Knochenneoplasien, die aus Resten der nicht zurückgebildeten Chorda dorsalis entstehen (Han et al. 2009). Sie zählen zu der Gruppe der embryonalen Restgewebstumoren und machen einen bis vier Prozent aller Knochentumoren aus (al-Mefty und Borba 1997). Von ihrem Ursprung ausgehend, sind die Chordome besonders in der Schädelbasisregion und im Bereich des Sakrums anzutreffen (Fletcher 2013; Freyschmidt et al. 2010; Walcott et al. 2012). Pathohistologisch stellen sich Chordome als lappenförmig angeordnete physaliforme Zellen dar, die kleine Kerne, Pleomorphismus und interzellulare Schleimhautbildung zeigen. Die hypochromatischen Zellkerne sind randständig verlagert und ähneln dem Bild einer Siegelringzelle (Seifert und Donath 1998) (Abbildung 1).

Obwohl es sich um einen langsam wachsenden Tumor handelt, wächst er lokal invasiv und destruktiv (Mendenhall et al. 2005). Unbehandelt versterben die Betroffenen binnen zwölf Monaten an der lokal progressiven Ausbreitung (Di Maio et al. 2011). Die Therapie der Wahl besteht zum jetzigen Zeitpunkt aus radikaler chirurgischer Resektion mit anschließender Bestrahlung. Trotz dieser Maßnahmen ist die Rezidivrate dieser Tumoren ausgesprochen hoch (Stacchiotti und Sommer 2015; Walcott et al. 2012). Dabei weisen 30 bis 40 \% der Erkrankten, häufig im späten Krankheitsverlauf oder nach lokalen Rezidiven, bevorzugt Metastasen im Bereich der Lunge, Leber, Knochen, Subkutis oder Lymphknoten auf (Fletcher 2013). Die Fünf- Jahres- Überlebensrate liegt bei 78,4 \%, das Fünf- JahreProgressionsfreie- Überleben bei 50,5 \% (Di Maio et al. 2011; Stacchiotti und Sommer 2015). Somit ist die Prognose bei Rezidiven als schlecht einzustufen (Tzortzidis et al. 2006). Die Behandlung von Chordomen bleibt daher eine Herausforderung.

Aktuelle Studien zeigen, dass die Chordomentstehung in der dritten embryonalen Woche aus dem Notochord (Chorda dorsalis) stattfindet (Sun et al. 2015; Wacker et al. 2002). Des Weiteren sondert der Notochord während dieser frühen Embryogenese diverse Signalmoleküle ab, unter anderem das Sonic- Hedgehog- Molekül (Shh), um die Proliferation, Diffe- 
renzierung und das Überleben der embryonalen Zellen zu regulieren (Cates et al. 2010; Hooper und Scott 2005; Kozmikova et al. 2013; Satoh et al. 2012; Sun et al. 2015).

Shh ist als wesentlicher Aktivator der Hedgehog- Signalkaskade essentiell für die Entwicklung diverser Organe wie Gehirn, Herz, Thymus, Lunge und Gliedmaßen (Chiang et al. 1996; Shah et al. 2004). Zahlreiche Studien zeigten bereits eine Beteiligung der HedgehogSignalkaskade am Tumorwachstum wie auch an Metastasenbildung in einer Vielzahl von menschlichen Tumoren, beispielsweise dem adamantinösen Kraniopharyngeom, Glioblastom, Medulloblastom und Rhabdomyosarkom (Andoniadou et al. 2012; Bar et al. 2007; Hooper und Scott 2005; Theunissen und Sauvage 2009; Yang et al. 2010).

An dieser Stelle stellt sich die Frage, ob extrazelluläre Signalwege wie der Hedgehog- Signalweg bei der Entstehung von Chordomen und deren Rezidiven involviert sind. Derzeit herrscht für die Behandlung von Chordomen und ihren Rezidiven keine chemotherapeutische Empfehlung, da sich bei lokal fortgeschrittenen und metastasierenden Chordomen bis dato kein Medikament bewährt hat (Stacchiotti und Sommer 2015). Beim Nachweis einer solchen Signalkaskade wäre eventuell ein therapeutischer Ansatz im Sinne eines Chemotherapeutikums denkbar. 


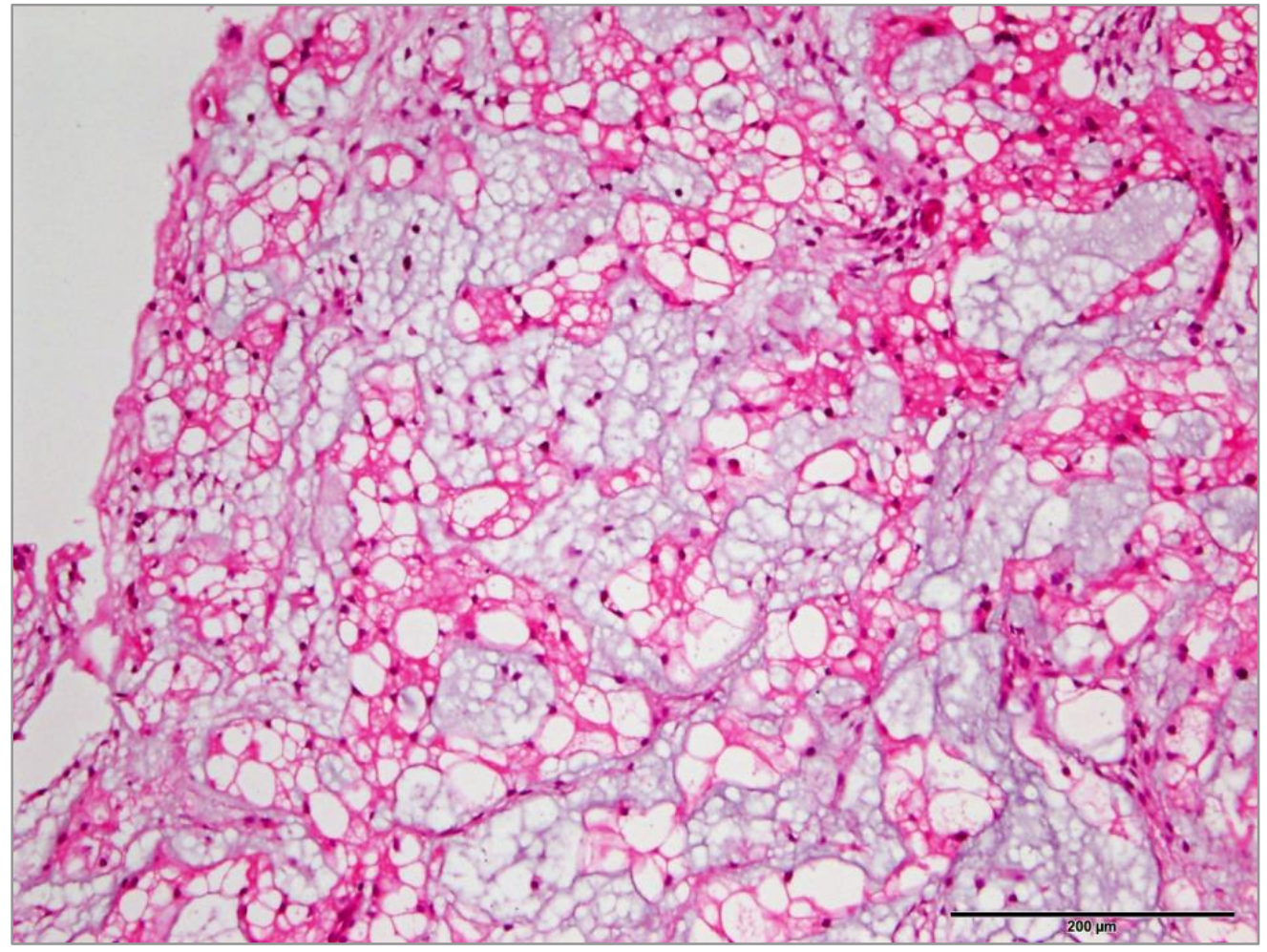

Abbildung 1: Die HE- Färbung eines kraniellen Chordomes zeigt die typischen lappenförmig angeordneten, physaliformen Zellen mit randständigen kleinen Zellkernen (Siegelringzellen) und interzellulärer Schleimhautbildung.

\subsection{Die Hedgehog- Signalkaskade}

Die Hedgehog $(H h)$ - Proteine sind extrazelluläre Signalmoleküle, die während der Embryonalentwicklung vieler Organismen eine zentrale Rolle spielen (Theunissen und Sauvage 2009). Sie wurden 1980 erstmals von Nüsslein-Volhard und Wischaus in Drosophila melanogaster beschrieben (Nüsslein-Volhard und Wieschaus 1980). Neben einer Vielzahl von Signalkaskaden reguliert die $H h$ - Signalkaskade während der Embryogenese die Proliferation, Differenzierung und das Überleben von Zellen. Auch im adulten Gewebe werden die Bildung und das Verbleiben von bestimmten Stamm- und Vorläuferzellen gesteuert (Hooper und Scott 2005) und Wundheilungsreaktionen moduliert (Justilien und Fields 2015; Omenetti et al. 2011). 
Bereits bei diversen anderen Tumoren, wie sowohl beim Basalzell-, Ovarial-, Prostata-, Mammakarzinom, beim klarzelligen Nierenzell- und Lungenkarzinom als auch beim Glioblastom, Medulloblastom, Rhabdomyosarkom und adamantinösen Kraniopharyngeom, wurde eine Überfunktion der Hh- Signalkaskade nachgewiesen (Andoniadou et al. 2012; Briscoe und Thérond 2013; Dormoy et al. 2009; Hahn et al. 1996; Hooper und Scott 2005; Kubo 2004; Lin et al. 2010; Liu et al. 2006; Low und Sauvage 2010; Wen et al. 2010). Somit ist die $\mathrm{Hh}$ - Signalkaskade am Tumorwachstum, als auch an der Metastasenbildung bei diversen Tumoren entscheidend beteiligt (Andoniadou et al. 2012).

Bei menschlichen Embryonen und Wirbeltieren besteht $\mathrm{H} h$ aus drei Untereinheiten, dem Sonic hedgehog (Shh), Desert hedgehog (Dhh) und Indian hedgehog (Ihh) (Katoh und Katoh 2006). Shh als wichtigstes $H h$ - Homolog ist essentiell für die Entwicklung diverser Organe wie Gehirn, Herz, Thymus, Lunge und Gliedmaßen (Chiang et al. 1996; Shah et al. 2004). Während Ihh hauptsächlich die Proliferation und Reifung von Chondrozyten während der Entstehung der Knorpelstrukturen reguliert (Razzaque et al. 2005), beeinflusst Dhh primär die Spermatogenese (Bitgood et al. 1996).

Für Hh existiert ein Rezeptor namens Patched (Ptch), der in Ptch1 und Ptch2 unterteilt wird (Justilien und Fields 2015; Smyth et al. 1999). Obwohl beide Untereinheiten ein ähnliches Reaktionsmuster aufweisen und mit gleicher Affinität an $H h$ binden, unterscheiden sie sich in ihren funktionellen Eigenschaften (Holtz et al. 2013; Rahnama et al. 2004). Ptch1 besitzt eine inhibierende Wirkung auf ein Sieben-Transmembranprotein (Smoothened (Smo)) (Corbit et al. 2005; Kim et al. 2009). Im inaktiven Zustand verbleibt das ZinkFinger-Transkriptions-Protein (Gli) an einen Komplex aus Proteinen Fused (Fu), Suppressor of Fused (SUFu) und Kinesin family member 7 (Kif7) im Zytoplasma der Zelle gebunden (Hui und Angers 2011; Katoh und Katoh 2006) (Abbildung 2). 


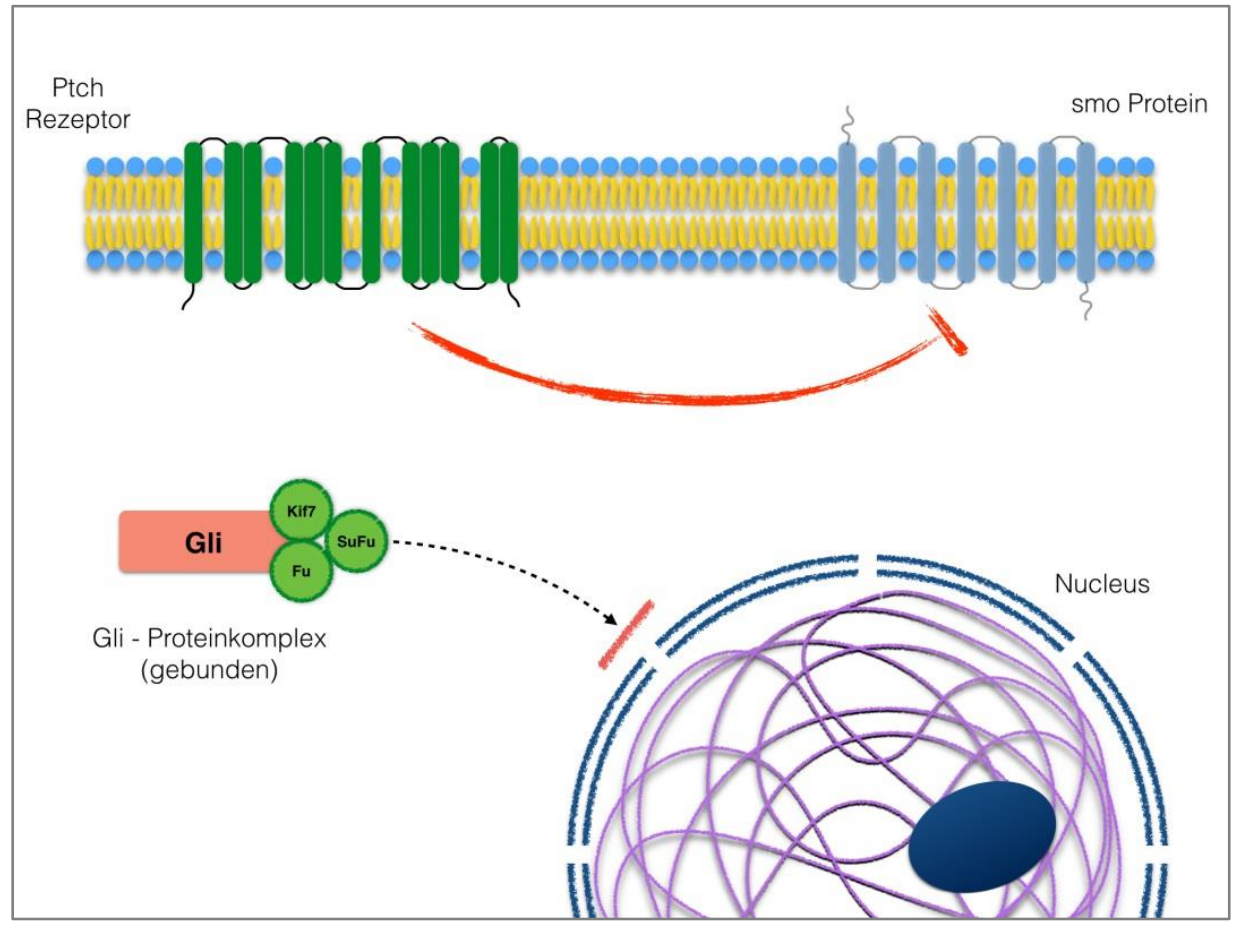

Abbildung 2: Shh- Signalkaskade in der „inaktiven“ Form (modifiziert nach Justilien und Fields 2015, S. 507).

Durch die Bindung von $\mathrm{Hh}$ an den Rezeptor Ptch1 wird die inhibitorische Wirkung von Smo aufgehoben, wodurch der Signalweg aktiviert wird (Katoh und Katoh 2006; Kim et al. 2009; Omenetti et al. 2011). Dabei kommt es zu einer Anreicherung von Smo in der Plasmamembran (Corbit et al. 2005; Incardona et al. 2002). Das Signal wird über das ZinkFinger-Transkriptions-Protein Gli, eingeteilt in Gli1, Gli2 und Gli3, ins Zellinnere transportiert (Hooper und Scott 2005; Hui und Angers 2011). Erst jetzt werden die Gli- Transkriptionsfaktoren freigesetzt, diffundieren in den Nukleus, um dort die Transkription ihrer Zielgene auszuüben (Nybakken und Perrimon 2002; Wen et al. 2010) (Abbildung 3). Zielgene sind unter anderem Apoptose (bcl2)- und Zellzyklus (CCND1, CCND2)- regulierende Gene, aber auch eigene Gene des Signalweges (Ptch und Gli1) (Ok et al. 2012). 


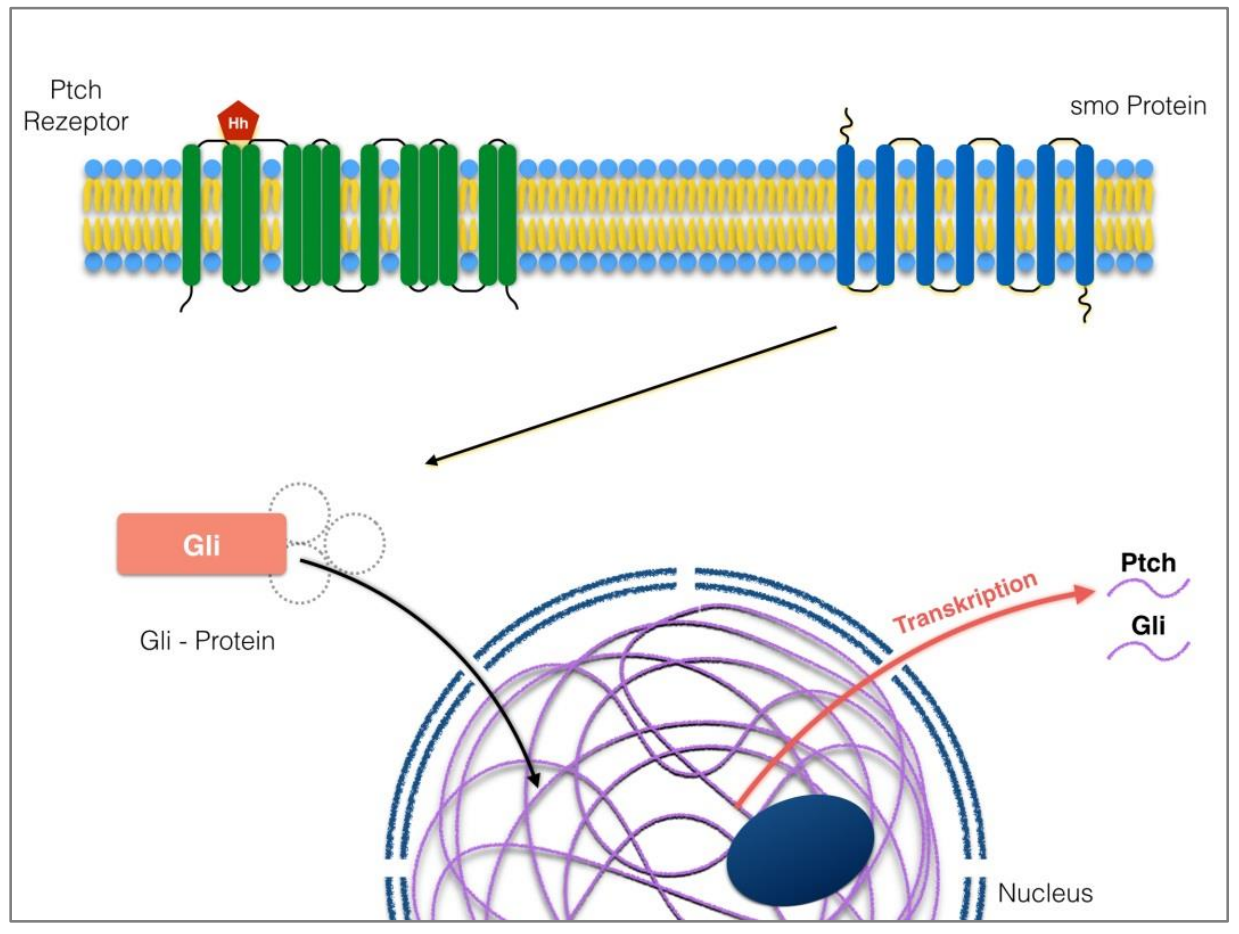

Abbildung 3: Shh- Signalkaskade in der „aktiven“ Form (modifiziert nach Justilien und Fields 2015, S. 507).

Um eine aktive $\mathrm{Hh} /$ Ptch- Signalkaskade nachzuweisen, werden sowohl Gli1 als auch Ptch1 als Marker genommen (Gu und Xie 2015; Katoh und Katoh 2006). Dafür eignet sich unter anderem die in situ- Hybridisierung (ISH), eine Untersuchungstechnik zur Lokalisation von DNA- oder RNA- Molekülen durch eine spezifische Anlagerung eines Nukleinsäurefragments (sogenannte Sonde) an die komplementäre Nukleinsäurezielsequenz im zu untersuchenden Präparat (Romeis 2010). Die Bezeichnung in situ (lateinisch am Ort) deutet darauf hin, dass der Nachweis der Sequenz in ursprünglicher Lokalisation, also im biologischen Präparat, erfolgt (Lang 2013). Ebenfalls kann immunhistochemisch durch die Expression von $\mathrm{Hh}$ - Proteinen während der Signalkaskade, wie zum Beispiel Shh und Gli1, eine Aktivität nachgewiesen werden (Freier et al. 2009).

Nach heutigem Wissensstand wirken Gli1 und Gli2 hauptsächlich als Aktivatoren der Zielgene, da sie den negativen Regulator Ptch1 inaktivieren. Gli3 wird als Repressor der ShhZielgene eingestuft (Kasper et al. 2006; Omenetti et al. 2011; Varjosalo et al. 2006). Jedoch aktiviert Gli3 durch einen positiven Rückkopplungsmechanismus wiederum die Gli1Transkription (Kappler 2006; Kasper et al. 2006). Da Gli1 zudem noch die Ptch-Transkription stimuliert, können sowohl Gli1 als auch Ptch1 als Zielgene und somit als zuverlässige 
Marker für eine aktive $\mathrm{Hh} /$ Ptch-Signalkaskade angesehen werden (Katoh und Katoh 2006) (Abbildung 4).

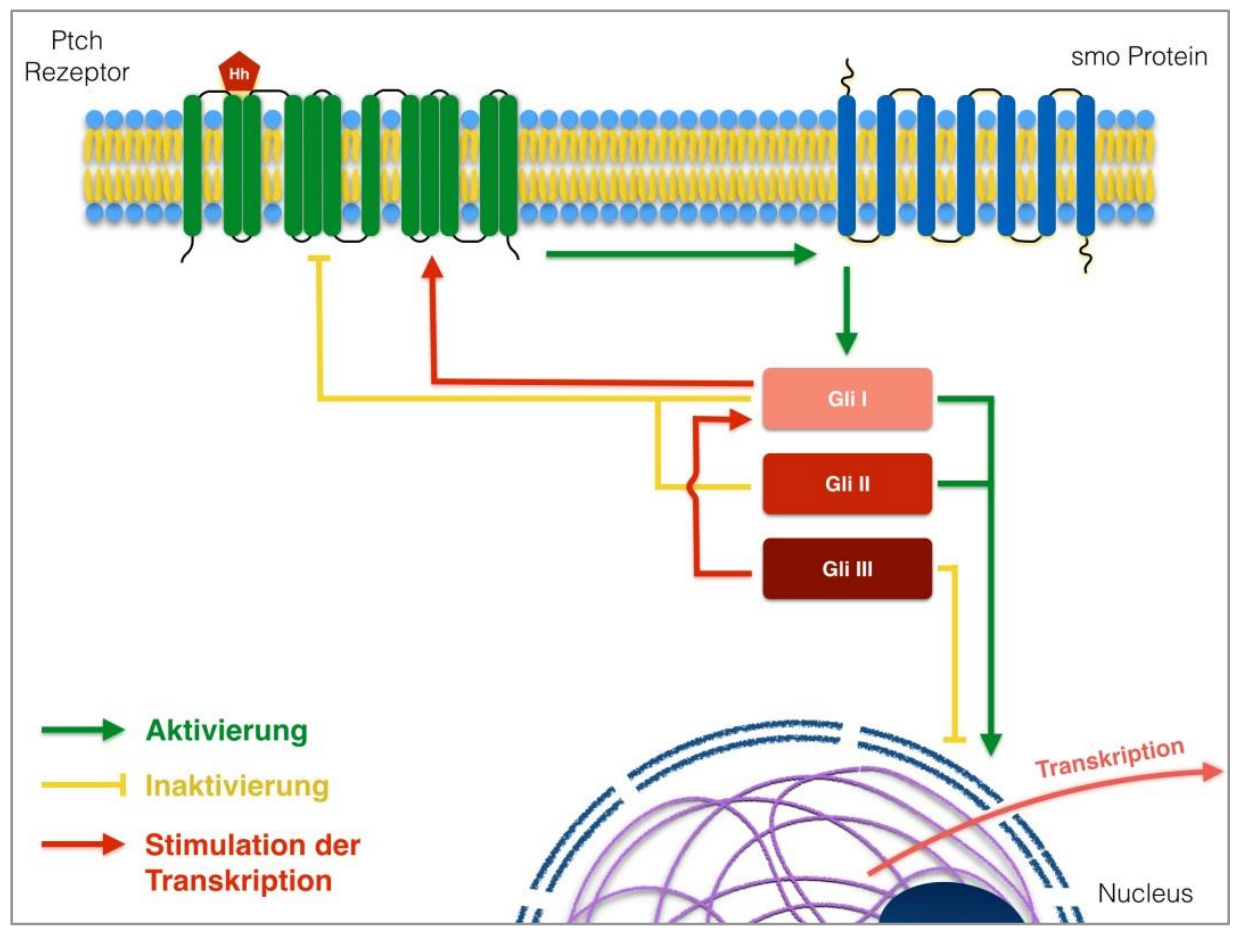

Abbildung 4: Gegenseitige Wechselbeziehungen innerhalb der Shh-Signalkaskade.

Es ist bereits bewiesen, dass Fehlfunktionen der Shh- Signalkaskade zur Ausbildung diverser Erkrankungen beziehungsweise zur Neubildung einer Neoplasie führen (Andoniadou et al. 2012) (Tabelle 1). Dabei ist Ptch1 als Tumorsuppressorgen (Ryan und Chiang 2012; Svärd et al. 2006) und Smo als Protoonkogen anzusehen (Hooper und Scott 2005; Rudin et al. 2009).

Neben dem beschriebenen regulären (kanonischen) Signalweg existieren auch nicht kanonische Mechanismen, die eine Gli1- Transkription aktivieren. Jedoch geschieht dies nicht über die Ebene von $H h$ und $S m o$, sondern über andere Signalwege, wie zum Beispiel durch die RAS (Rat Sarcoma)- und die TGF $\beta$ (Transforming Growth Factor Beta)- Signalkaskade (Gu und Xie 2015; Lauth und Toftgård 2007). 
Tabelle 1: Fehlregulationen der Shh-Signalkaskade, die zur Neubildung einer Neoplasie führen (modifiziert nach Hooper und Scott 2005, S. 306).

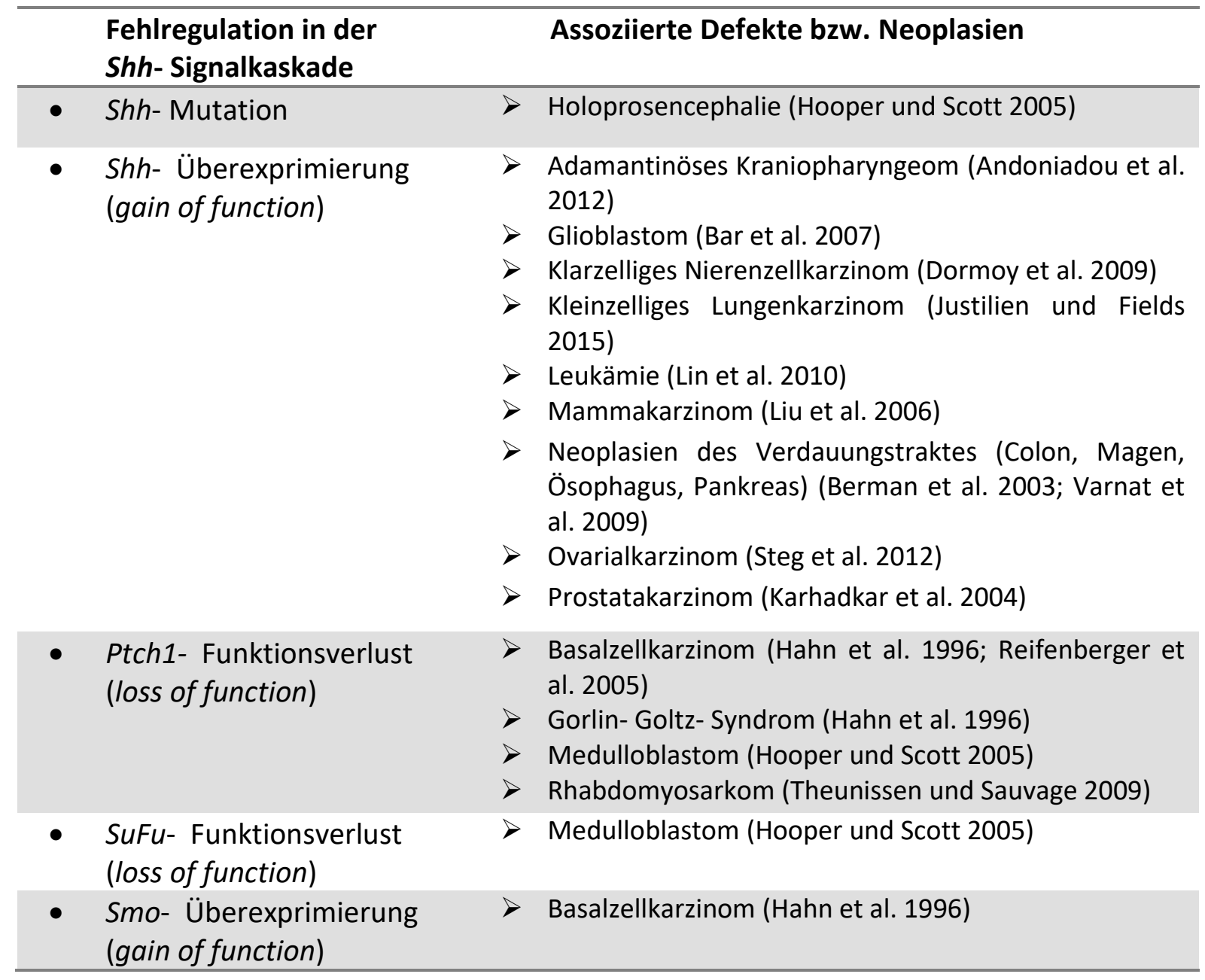

\subsection{Zielsetzung der Arbeit}

Anhand der durchgeführten Untersuchung soll eine mögliche Involvierung der Shh- Signalkaskade bei der Entstehung von Chordomen und deren Rezidiven nachgewiesen werden. Da zurzeit für die Therapie von Chordomen und deren Rezidiven keine standardisierte chemotherapeutische Empfehlung besteht, wäre beim Nachweis einer aktiven ShhSignalkaskade eventuell ein chemotherapeutischer Ansatz zur Behandlung dieser Patienten denkbar. 


\subsection{Patientenkollektiv und Gewebematerialien}

In den Jahren 1982 bis 2012 wurden insgesamt zwölf (60 \%) Patienten an einem kraniellen und acht (40\%) Patienten an einem spinalen Chordom operiert. Von den zwölf kraniell erkrankten Patienten erlitten fünf (42\%) Patienten ein kranielles erstes Rezidiv und zwei (17 \%) Patienten ein kranielles zweites Rezidiv. Von den acht spinal erkrankten Patienten wiesen fünf (63 \%) Patienten ein spinales erstes Rezidiv auf, weswegen eine erneute Operation durchgeführt werden musste. Von allen genannten Patienten befanden sich 15 (75 \%) von der Diagnosestellung bis zur letzten Operation in der vollständigen Therapie der Neurochirurgie der Universitätsmedizin Göttingen. Fünf (25 \%) von 20 Patienten wurden von anderen Krankenhäusern, in denen die erste Operation stattfand, zur Weiterbehandlung überwiesen. Die Folgeoperationen und die gesamte Weiterbehandlung fanden in der Universitätsmedizin Göttingen statt. Sechs (50 \%) der kraniell erkrankten Patienten waren weiblich und sechs (50 \%) männlich, bei den spinal erkrankten Patienten waren fünf (62 \%) weiblich und drei (38 \%) männlich. Das Durchschnittsalter der kraniell erkrankten Patienten zum Zeitpunkt der Erstdiagnose lag bei 49 Jahren, dabei war der jüngste Patient zehn, die älteste Patientin 89 Jahre alt. Das Durchschnittsalter bei den spinal erkrankten Patienten lag bei 57 Jahren, dabei war der jüngste Patient 18, die älteste Patientin 80 Jahre alt (Tabelle 2).

Tabelle 2: Übersicht des Patientenkollektivs $(n=20)$

\begin{tabular}{|c|c|c|}
\hline & Kranielles Chordom & Spinales Chordom \\
\hline Patientenanzahl $(n=20)$ & $12(60 \%)$ & $8(40 \%)$ \\
\hline weiblich & $6(50 \%)$ & $5(62 \%)$ \\
\hline männlich & $6(50 \%)$ & $3(38 \%)$ \\
\hline 1. Rezidiv - Gesamtzahl & $5(42 \%)$ & $5(63 \%)$ \\
\hline weiblich & $4(80 \%)$ & $2(40 \%)$ \\
\hline männlich & $1(20 \%)$ & $3(60 \%)$ \\
\hline 2. Rezidiv - Gesamtzahl & $2(17 \%)$ & 0 \\
\hline weiblich & $1(50 \%)$ & 0 \\
\hline männlich & 1 (50 \%) & 0 \\
\hline Durchschnittsalter & $49 \mathrm{~J}$. & $57 \mathrm{~J}$. \\
\hline Alterspanne & 10 J.- 89 J. & $18 \mathrm{~J} .-80 \mathrm{~J}$. \\
\hline
\end{tabular}


Von insgesamt 14 (70 \%) Patienten war im neuropathologischen Zentralarchiv der Universitätsmedizin Göttingen brauchbares Tumormaterial vorhanden, welches für die Immunhistochemie und in situ- Hybridisierung verwendet wurde.

Die 14 Patienten unterteilten sich in acht (57\%) kraniell und sechs (43\%) spinal erkrankte Patienten. Von den acht (57\%) Patienten mit einem kraniellen Chordom waren insgesamt 14 Tumorblöcke vorhanden, davon sieben Primärtumoren, fünf erste Rezidive und zwei zweite Rezidive (Anhang 6.1 Tabelle 9). Von den sechs (43\%) Patienten mit einem spinalen Chordom waren insgesamt 18 Tumorblöcke vorhanden, davon zwölf Primärtumoren und sechs erste Rezidive (Anhang 6.1 Tabelle 10).

\subsection{Einbetten von Geweben}

Intraoperativ entnommene Proben wurden routinemäßig im neuropathologischem Labor der Universitätsmedizin Göttingen im Gewebeeinbettautomat Shandon Excelsior ${ }^{\mathrm{TM}}$ zunächst in aufsteigender Alkoholreihe (50\%, 70 \%, $80 \%, 80 \%, 96 \%, 100 \%, 100 \%)$ entwässert, mit Xylol behandelt und in Paraffin eingebettet. Nach der Gesamteinbettdauer im Automaten von circa 16 Stunden, wurden die Biopsien in Einbettförmchen mit flüssigem Paraffin ausgegossen und auf einer Kühlplatte abgekühlt.

Für die in situ- Hybridisierung, welche zur Markierung sowohl von spezifischen DNA- als auch RNA- Molekülen dient (Romeis 2010), gilt ein RNasen- freies Arbeiten als Voraussetzung. Somit soll eine mögliche hydrolytische Spaltung der RNA- Ketten verhindert werden (Mülhardt 2009). Für die Inaktivierung der ungewünschten RNasen wurden die Wasserbäder über Nacht mit Dimethylpyrocarbonat (DMPC) behandelt und anschließend autoklaviert. Das DMPC zerfällt nach diesem Schritt zu $\mathrm{CO}_{2}$ und Ethanol. DMPC bindet an primäre und sekundäre Amine und führt zu kovalenten Bindungen, sodass die RNasen- Aktivität zerstört wird (Mülhardt 2009). Generell wurden bei allen Vorgängen nur neue, unbenutzte oder mit entsprechender Desinfektion (RNase away ${ }^{\circledR}$ ) behandelte Geräte und Materialien benutzt, um eine Kontamination mit RNasen auszuschließen beziehungsweise zu vermeiden. 
Aus den abgekühlten Paraffinblöcken wurden am Schlittenmikrotom Schnitte von circa 1 $\mu \mathrm{m}$ Dicke angefertigt und auf Objektträger aus dem kalten Wasser aufgezogen. Daraufhin wurden die aufgezogenen Objektträger im warmen Wasser $\left(56-58^{\circ} \mathrm{C}\right)$ behandelt und mit Filterpapier vom restlichen Wasser befreit. Anschließend wurden die Paraffinschnitte in Glasküvetten über Nacht bei $57^{\circ} \mathrm{C}$ getrocknet, bevor sie für die Immunhistochemie und in situ- Hybridisierung benutzt wurden.

\subsection{Immunhistochemie}

Die immunhistochemischen Untersuchungen wurden an allen Proben von kraniellen und spinalen Chordomen mit folgenden Antikörpern durchgeführt: Anti- SHH (rabbit) (1: 500), Anti- Gli1 (rabbit) (1: 100), EnVision Polyclonal rabbit/ mouse (1: 1) (Tabelle 3). Alle Schnitte, sowohl Positiv- als auch Negativkontrollen, wurden unter identischen Bedingungen bearbeitet. Als Negativkontrolle dienten die Schnitte ohne Inkubation mit dem Primärantikörper.

Die Gewebeschnitte wurden drei Mal für zehn Minuten in Xylol entparaffiniert und in einer absteigenden Alkokolreihe (96\%, $96 \%, 75 \%, 50 \%, 30 \%$ bis DMPC- $\mathrm{H}_{2} \mathrm{O}$ ) rehydriert. Für den Primärantikörper Shh wurden die Gewebeschnitte zur Antigendemaskierung (Antigen Retrieval) 20 Minuten lang mit Citrat pH 6,0 in der Mikrowelle bei $80^{\circ} \mathrm{C}$ vorbehandelt, anschließend für 30 Minuten in TBS/ 0,1 \% Triton X-100 gewaschen. Für den Primärantikörper Gli1 war keine weitere Vorbehandlung notwendig, da hierfür das Epitop frei zugänglich war.

Um unspezifische Bindungsstellen zu vermeiden, wurden die Gewebeschnitte für $20 \mathrm{Mi}$ nuten in $\mathrm{H}_{2} \mathrm{O}_{2} /$ TBS $3 \%$, für zehn Minuten in TBS/ 0,1 \% Triton X-100 und anschließend für 20 Minuten mit 0,2 \% Casein geblockt. Der Primärantikörper wurde für 90 Minuten bei Raumtemperatur auf das Gewebe appliziert und mit TBS/ 0,1 \% Triton X-100 gespült. Danach wurde der Sekundärantikörper für 30 Minuten bei Raumtemperatur auf die Schnitte aufgetragen. Nach erneutem Spülen mit TBS/ 0,1 \% Triton X-100 erfolgte die Farbreaktion für fünf bis 30 Minuten mit einer AEC-Färbelösung. Nach einer Gegenfärbung mit Hämatoxylin wurden die Schnitte mit einem wässrigen Eindeckmittel zur Konservierung (Aqua- 
tex ${ }^{\circledast}$ ) eingedeckt. Für die Immunhistochemie benötigte Stammlösungen, Chemikalien, Laborwaren und -geräte sind im Anhang (Kapitel 6.3; 6.4; 6.5; 6.6) aufgelistet.

Tabelle 3: Verdünnung der Primär- und Sekundärantikörper für die Immunhistochemie

\begin{tabular}{ll}
\hline Antikörper & Verdünnung \\
\hline Anti- SHH (rabbit), abcam, Cambridge, ab 73958 & $1: 500$ in TBS/ 0,1 \% Triton X-100 \\
Anti- Gli1 (rabbit), Rockland Immunochemicals Inc., & $1: 100$ in TBS/ 0,1 \% Triton X-100 \\
Gilbertsville, 100-401-223 & $1: 1$ in TBS \\
EnVision Polyclonal rabbit/mouse HRP, Dako GmbH, & \\
Hamburg, K5007 & \\
\hline
\end{tabular}

\section{4. in situ- Hybridisierung}

Die für die in situ- Hybridisierung benötigten Digoxigenin- markierten Sonden Ptch1 und Gli1 wurden im Institut für Humangenetik der Universitätsmedizin Göttingen hergestellt und freundlicherweise für die in situ- Hybridisierung zur Verfügung gestellt. Alle Schnitte, sowohl Positiv- als auch Negativkontrollen, wurden unter identischen Bedingungen bearbeitet. Als Negativkontrolle dienten die Schnitte, die mit den Sonden Ptch1 Sense und Gli1 Sense inkubiert wurden.

Die Paraffinschnitte wurden für zwei Stunden bei $57^{\circ} \mathrm{C}$ im Hybridisierungsofen inkubiert, zweimal für 20 Minuten in Xylol entparaffiniert und in einer absteigenden Ethanolreihe (96 \%, 96 \%, 75 \%, 50 \%, 30 \%, DMPC- H2O) jeweils für drei Minuten rehydriert. Anschließend folgte eine Fixierung in $4 \%$ PFA bei $4^{\circ} \mathrm{C}$ für 20 Minuten. Bei Raumtemperatur wurden die Gewebeschnitte für zehn Minuten in $0,2 \mathrm{M} \mathrm{HCl}$ zur Proteindenaturierung überführt und daraufhin dreimal für zehn Minuten in TBS-Puffer bei Raumtemperatur gewaschen. Danach wurden die Schnitte mit Proteinase K- Puffer für 30 Minuten bei $37^{\circ} \mathrm{C} \mathrm{im}$ Hybridisierungsofen versehen. Es folgten erneute Waschvorgänge im TBS- Puffer, einmal für fünf Minuten bei $-20^{\circ} \mathrm{C}$ zum Stoppen der Proteinase K- Reaktion und dreimal bei Raumtemperatur für jeweils zehn Minuten. Zur Inaktivierung der endogenen alkalischen 
Phosphatase wurden 0,5 \% Essigsäureanhydrid für zehn Minuten hinzugegeben. Die Gewebeschnitte wurden erneut dreimal für zehn Minuten in TBS- Puffer bei Raumtemperatur gewaschen und anschließend in einer aufsteigenden Ethanolreihe (30 \%, 50 \%, 75 \%, 96\%, $96 \%$, Chloroform) dehydriert. Die Schnitte wurden am selben Tag für die Hybridisierung verwendet. Pro $1 \mathrm{ml}$ Hybridisierungsmix wurden $50 \mu$ l Lachsspermien- DNA hinzugegeben und sowohl die Sense- als auch die Antisense- Sonden Ptch1 und Gli1 1: 500 in diesem Hybridisierungspuffer verdünnt. $50 \mu \mathrm{l}$ Hybridisierungsmix wurde auf jeden Gewebeschnitt pipettiert und luftblasenfrei mit einem Deckgläschen abgedeckt. Zusammenfassend wurden pro Gewebebiopsie vier Paraffinschnitte genommen: Ptch1 Sense (Ptch1 S), Ptch1 Antisense (Ptch1 AS), Gli1 Sense (Gli1 S) und Gli1 Antisense (Gli1 AS). Alle Gewebeschnitte wurden in eine feuchte Kammer mit DMPC- $\mathrm{H}_{2} \mathrm{O}$ aufbewahrt und für vier Minuten auf eine $95^{\circ} \mathrm{C}$ warme Heizplatte gestellt. Nach Auflösen der RNA- Sekundärstruktur und Hemmung der endogenen Phosphatase wurde die feuchte Kammer über Nacht bei $62^{\circ} \mathrm{C}$ inkubiert. Am nächsten Tag wurde die Kammer geöffnet und die Deckgläschen vorsichtig entfernt. Es folgten zwei Waschvorgänge für zehn Minuten bei Raumtemperatur im Waschpuffer I, zwei im weniger konzentrierten Waschpuffer II für zehn Minuten bei $62^{\circ} \mathrm{C}$ und zwei in TBS für zehn Minuten bei Raumtemperatur auf dem Plattformschüttler. Zum Vermeiden von unspezifischen Bindungen wurden $120 \mu \mathrm{l}$ Block-Mix pro Gewebeschnitt aufgetragen und diese in der feuchten Kammer für 15 Minuten bei Raumtemperatur inkubiert. Der überschüssige Blockmix wurde vorsichtig entfernt und $120 \mu$ les AntiDigoxigenin Fab fragments/ AP-Mix pro Gewebeschnitt pipettiert und für zwei Stunden bei Raumtemperatur in der feuchten Kammer inkubiert. Nach Ablauf der Zeit wurden die Gewebeschnitte nochmals dreimal in TBS für zehn Minuten bei Raumtemperatur gewaschen und zum Anfärben in NBT/ BCIP- NTM- Substratpuffer solange im Dunkeln bei $4^{\circ} \mathrm{C}$ gelagert, bis eine ausreichende Signalintensität erreicht wurde. Dabei erfolgte ein täglicher Wechsel der Lösung. Abschließend wurden die Gewebeschnitte zur Konservierung mit einem wässrigen Eindeckmittel (Aquate ${ }^{\circledR}$ ) eingedeckt. Die bei der in situ- Hybridisierung verwendeten Stammlösungen, Chemikalien, Laborwaren und -geräte sind im Anhang (Kapitel 6.3; 6.4; 6.5; 6.6) aufgelistet. 


\subsection{Auswertungskriterien}

Alle immunohistochemisch untersuchten Gewebeproben wurden mikroskopisch anhand ihrer Färbungsintensität im Zytoplasma und in der Membran der Tumorzellen mittels eines Scoring-Systems nach Rüschoff et al. (Rüschoff et al. 2009) bewertet (Tabelle 4). Somit wurde jeweils der Score für Shh und Gli1 in den Tumorzellen bestimmt und alle Ergebnisse gegeneinander zum Vergleich aufgestellt.

Tabelle 4: Scoring-System nach Rüschoff et al. 2009 für die Immunhistochemie in den Tumorzellen.

\begin{tabular}{ll}
\hline Score $\mathbf{0}$ & Keine Färbung \\
\hline Score $\mathbf{1}$ & Kaum sichtbare Färbung im Zytoplasma/ in der Membran $<10 \%$ \\
\hline Score $\mathbf{2}$ & $\begin{array}{l}\text { Schwach- mäßige, ringförmige Färbung im Zytoplasma/ in der Membran } \\
>10 \% \text { und }</=30 \%\end{array}$ \\
\hline Score 3 & Starke, ringförmige Färbung im Zytoplasma/ in der Membran $>30 \%$ \\
\hline
\end{tabular}

Die Gewebeschnitte der in situ- Hybridisierung wurden, jeweils für Ptch1 und Gli1, mit einer sichtbaren Kernfärbung in den Tumorzellen als positiv (+) bewertet. Eine fehlende Kernfärbung in den Tumorzellen wurde mit negativ (-) vermerkt. Anschließend wurden die Ergebnisse beider Verfahren miteinander verglichen. 


\section{Ergebnisse}

\subsection{Immunhistochemie}

Insgesamt wurden 14 (100 \%) kranielle Chordome von acht Patienten immunhistochemisch auf die Proteinexpression von Shh und Gli1 untersucht. Die 14 Tumorproben teilten sich in sieben Primärtumoren, fünf erste Rezidive und zwei zweite Rezidive auf. Es reagierten zehn (71 \%) Proben, genauer alle sieben Primärtumoren und drei erste Rezidive von sieben (87,5 \%) Patienten sowohl mit Shh (+) als auch Gli1 (+). Die übrigen vier (29\%) kraniellen Proben, die von zwei (25\%) Patienten stammen, waren zwei erste und zwei zweite Rezidive und zeigten leidglich eine positive Gli1- Reaktion. Insgesamt reagierte Gli1 mit 14 (100 \%) positiven Ergebnissen bei allen acht (100 \%) Patienten geringfügig stärker als Shh mit zehn (71 \%) positiven Proben bei sieben (88 \%) Patienten (Tabelle 5).

Tabelle 5: Immunhistochemie: Verteilung und Reaktionsstärke der kraniellen Chordome bei acht Patienten und 14 Proben, unterteilt in sieben Primärtumoren, fünf erste Rezidive und zwei zweite Rezidive.

\begin{tabular}{|l|cc|cc|cc|}
\hline $\begin{array}{l}\text { Kranielle } \\
\text { Chordome }\end{array}$ & $\begin{array}{c}\text { Shh (t) } \\
\text { Primär- } \\
\text { tumoren }\end{array}$ & $\begin{array}{c}\text { Gli1 (+) } \\
\text { Primär- } \\
\text { tumoren }\end{array}$ & $\begin{array}{c}\text { Shh (t) } \\
\text { 1. Rezidive }\end{array}$ & $\begin{array}{c}\text { Gli1 (t) Rezidive } \\
\text { 1umh }\end{array}$ & $\begin{array}{c}\text { Shh }(+) \\
\text { 2. Rezidive }\end{array}$ & $\begin{array}{c}\text { Gli1 (+) } \\
\text { 2. Rezidive }\end{array}$ \\
\hline Score 0 & $0(0 \%)$ & $0(0 \%)$ & $2(40 \%)$ & $0(0 \%)$ & $2(29 \%)$ & $0(0 \%)$ \\
\hline Score 1 & $3(43 \%)$ & $2(29 \%)$ & $0(0 \%)$ & $0(0 \%)$ & $0(0 \%)$ & $1(50 \%)$ \\
\hline Score 2 & $1(14 \%)$ & $1(14 \%)$ & $3(60 \%)$ & $2(40 \%)$ & $0(0 \%)$ & $1(50 \%)$ \\
\hline Score 3 & $3(43 \%)$ & $4(57 \%)$ & $0(0 \%)$ & $3(60 \%)$ & $0(0 \%)$ & $0(0 \%)$ \\
\hline
\end{tabular}

Zudem wurden 18 (100 \%) spinale Chordome, davon zwölf Primärtumoren und sechs erste Rezidive, von sechs Patienten immunhistochemisch auf die Expression von Shh und Gli1 untersucht. Es reagierten 17 (94\%) Proben, genauer elf Primärtumoren und alle sechs ersten Rezidive, von allen sechs Patienten sowohl Shh (+) als auch Gli1 (+). Eine spinale Probe (6 \%) von einem (17 \%) Patienten zeigte lediglich für Shh ein positives Ergebnis, dabei handelte es sich um einen Primärtumor. Ferner reagierte bei allen sechs Patienten Shh (+) mit 18 Proben geringfügig häufiger als Gli1 (+) mit 17 Proben (Tabelle 6). 
Tabelle 6: Immunhistochemie: Verteilung und Reaktionsstärke der spinalen Chordome bei sechs Patienten und 18 Proben, unterteilt in zwölf Primärtumoren und sechs erste Rezidive.

\begin{tabular}{|c|c|c|c|c|}
\hline $\begin{array}{l}\text { Spinale } \\
\text { Chordome }\end{array}$ & $\begin{array}{l}\text { Shh (+) } \\
\text { Primär- } \\
\text { tumoren }\end{array}$ & $\begin{array}{l}\text { Gli1 (+) } \\
\text { Primär- } \\
\text { tumoren }\end{array}$ & $\begin{array}{l}\text { Shh (t) } \\
\text { 1. Rezidive }\end{array}$ & $\begin{array}{c}\text { Gli1 (+) } \\
\text { 1. Rezidive }\end{array}$ \\
\hline Score 0 & 0 (0 \%) & 1 (8 \%) & 0 (0 \%) & $0(0 \%)$ \\
\hline Score 1 & 5 (42 \%) & $5(42 \%)$ & 2 (33 \%) & 1 (17\%) \\
\hline Score 2 & 5 (42 \%) & 5 (42 \%) & 1 (17 \%) & 2 (33\%) \\
\hline Score 3 & 2 (16 \%) & $1(8 \%)$ & 3 (50 \%) & 3 (50 \%) \\
\hline
\end{tabular}

Zusammenfassend zeigten alle 19 kranielle und spinale Primärtumoren von insgesamt 14 Patienten eine positive immunhistochemische Reaktion für Shh und/ oder Gli1. Ebenfalls wiesen sowohl alle elf kraniellen und spinalen ersten Rezidive als auch die zwei kraniellen zweiten Rezidive, von insgesamt 14 Patienten, eine positive immunhistochemische Reaktion für Shh und/ oder Gli1 auf.

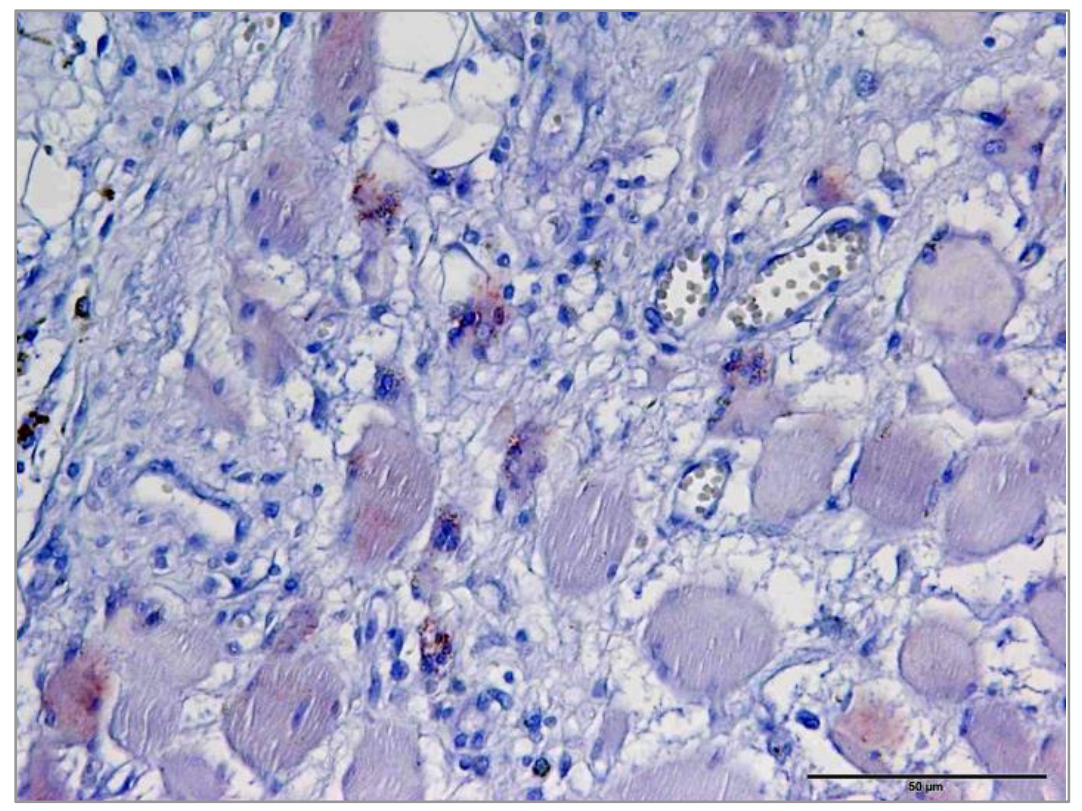

Abbildung 5: Immunhistochemische Färbung der Gli1- Expression bei einem spinalen Chordom. Die Expressionsstärke der zytoplasmatischen granulären Färbung der Tumorzellen entspricht dem Score 1 (Vergrößerung $400 \mathrm{x}$ ). 


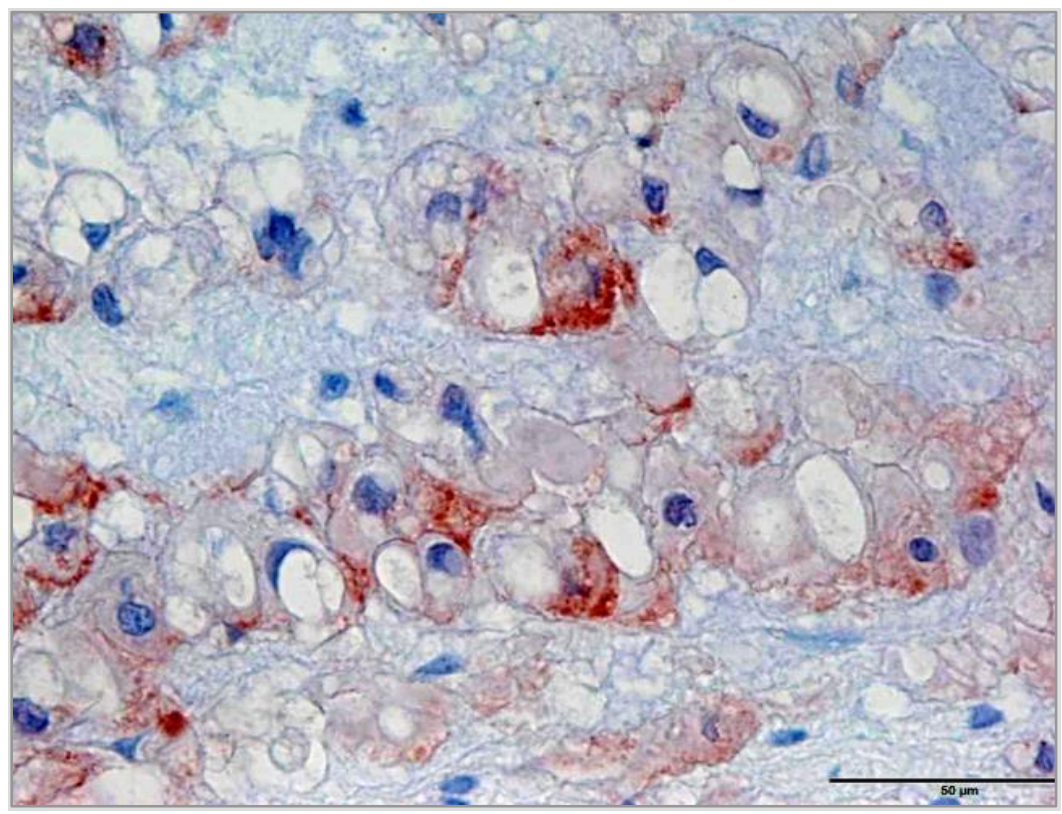

Abbildung 6: Immunhistochemische Färbung der Gli1- Expression bei einem kraniellen Chordom. Die Expressionsstärke der zytoplasmatischen granulären Färbung der Tumorzellen entspricht dem Score 3 (Vergrößerung $400 \mathrm{x}$ ).

\section{2. in situ- Hybridisierung}

Insgesamt wurden 14 kranielle Chordome, unterteilt in sieben Primärtumoren, fünf erste Rezidive und zwei zweite Rezidive von acht (100\%) Patienten mittels in situ- Hybridisierung auf die Expression von Ptch1 und Gli1 untersucht. Bei vier (57 \%) kraniellen Primärtumoren von drei (38\%) Patienten war eine positive Reaktion sichtbar. Davon reagierten zwei (29 \%) Primärtumoren Ptch1 (+) und zwei (29 \%) Proben Gli1 (+).

Die ersten und zweiten kraniellen Rezidive zeigten keine Reaktion auf die Marker Ptch1 und Gli1 (Tabelle 7).

Tabelle 7: in situ- Hybridisierung: Reaktion der kraniellen Chordome bei acht Patienten und 14 Proben, unterteilt in sieben Primärtumoren, fünf erste Rezidive und zwei zweite Rezidive.

\begin{tabular}{|l|l|l|l|}
\hline $\begin{array}{l}\text { Kranielle } \\
\text { Chordome }\end{array}$ & $\begin{array}{c}\text { Primärtumoren } \\
n=7\end{array}$ & 1. Rezidive & 2. Rezidive \\
\hline Ptch1 (+) & $2(29 \%)$ & $0(0 \%)$ & $0(0 \%)$ \\
\hline Gli1 (+) & $2(29 \%)$ & $0(0 \%)$ & $0(0 \%)$ \\
\hline
\end{tabular}


Außerdem wurden 18 spinale Chordome, unterteilt in zwölf Primärtumoren und sechs erste Rezidive, von sechs (100 \%) Patienten auf die Expression von Ptch1 und Gli1 mittels in situ- Hybridisierung getestet. Davon zeigten acht (67 \%) Primärtumoren von drei (50 \%) Patienten eine positive Reaktion, drei (25\%) Proben von zwei (33 \%) Patienten Ptch1 (+) und fünf (42\%) Proben von drei (50\%) Patienten Gli1 (+). Auch bei den ersten spinalen Chordomrezidiven fiel die Reaktion für Ptch1 und Gli1 negativ aus (Tabelle 8).

Sowohl bei den kraniellen als auch bei den spinalen Primärtumoren und Rezidiven war die Expression von Ptch1 und Gli1 nur im Kern der Tumorzellen sichtbar (Abbildung 7). Die benachbarten Stromazellen zeigten keine positive Expression für Ptch1 und Gli1.

Tabelle 8: in situ- Hybridisierung: Reaktion der spinalen Chordome bei sechs Patienten und 18 Proben, unterteilt in zwölf Primärtumoren und sechs erste Rezidive.

\begin{tabular}{|l|l|l|}
$\begin{array}{l}\text { Spinale } \\
\text { Chordome }\end{array}$ & $\begin{array}{c}\text { Primärtumoren } \\
n=12\end{array}$ & 1. Rezidive \\
\hline Ptch1 (+) & $3(25 \%)$ & $0(0 \%)$ \\
\hline Gli1 (+) & $5(42 \%)$ & $0(0 \%)$ \\
\hline
\end{tabular}



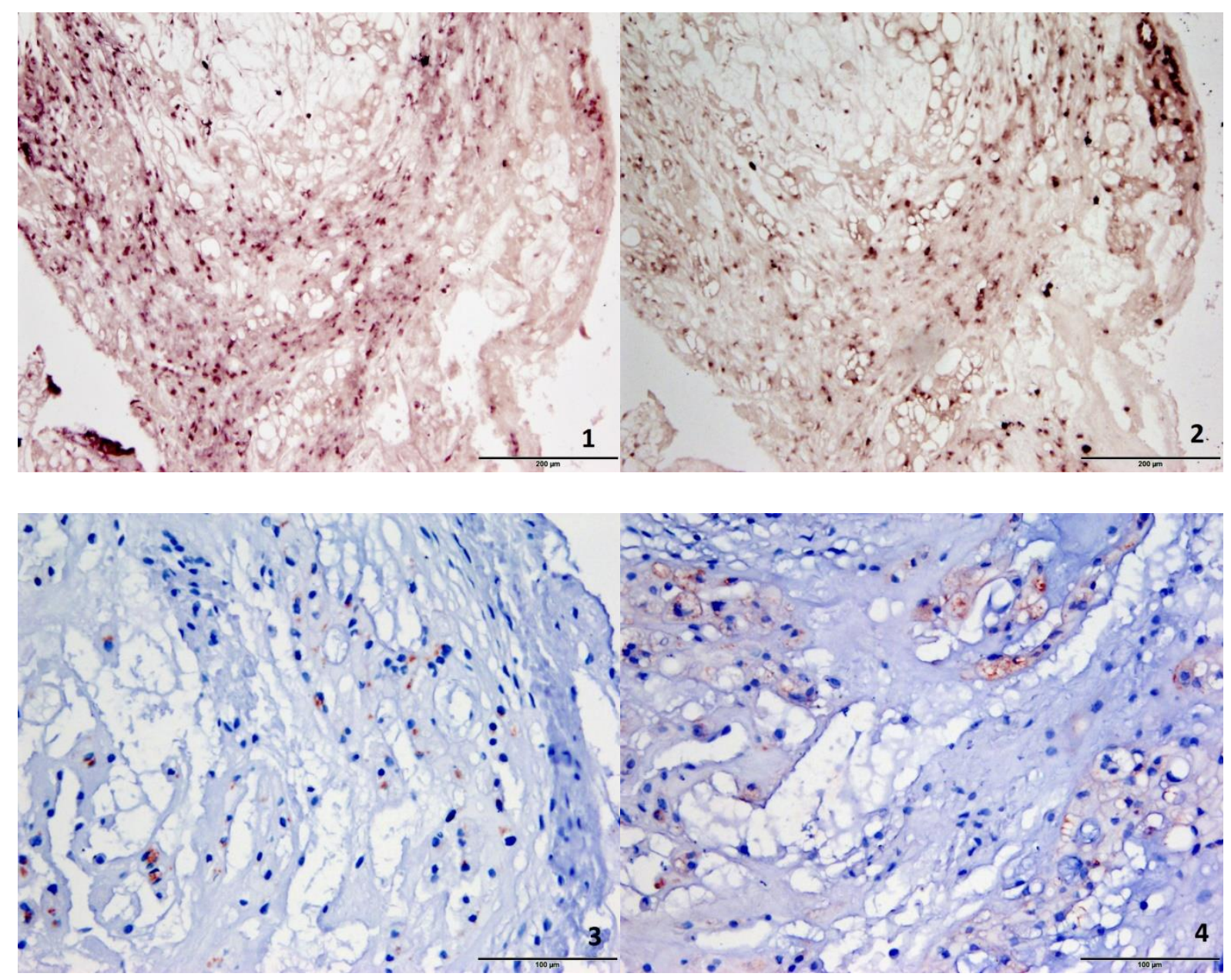

Abbildung 7: Gegenüberstellung einer kraniellen Chordomprobe von einem Patienten nach positiver in situ- Hybridisierung (Ptch1 (+), Gli1 (+)) und immunhistochemischer Färbung (Shh (+) und Gli1 (+)) im Vergleich:

Bild 1: in situ- Hybridisierung Ptch1 (+) in $100 \times$ Vergrößerung.

Bild 2: in situ- Hybridisierung Gli1 (+) in $100 \times$ Vergrößerung.

Bild 3: Immunhistochemie Shh (+), Score 2, in $200 \times$ Vergrößerung.

Bild 4: Immunhistochemie Gli1 (+), Score 2, in 200 x Vergrößerung. 
Chordome sind seltene, langsam wachsende und maligne Knochenneoplasien, die während der Embryogenese aus Resten der nicht zurückgebildeten Chorda dorsalis (Notochord) entstehen (Han et al. 2009; Wacker et al. 2002). Die Betroffenen versterben unbehandelt binnen zwölf Monaten am lokal invasiven, destruktiven Wachstum und der lokal progressiven Ausbreitung des Tumors (Di Maio et al. 2011; Mendenhall et al. 2005). Die Therapie der Wahl bei der Behandlung von Chordomen ist derzeit die chirurgische Resektion mit anschließender Bestrahlung (Stacchiotti und Sommer 2015). Dabei bietet die klassische Strahlentherapie mit hochenergetischen Photonen den Erkrankten eine kurzfristige Verbesserung des Krankheitsbildes (Schulz-Ertner et al. 2004). Für eine begleitende Chemotherapie in der Behandlung von Chordomen und deren Rezidiven besteht bisher aufgrund der Seltenheit der Tumoren keine evidenzbasierte Studie (Ptaszyński et al. 2009; Stacchiotti und Sommer 2015).

Der Notochord, aus dem unter anderem die Chordome hervorgehen, exprimiert diverse Signalmoleküle, unter anderem das Sonic- Hedgehog- Molekül, um die Proliferation, Differenzierung und das Überleben von embryonalen Zellen zu steuern (Cates et al. 2010; Kozmikova et al. 2013; Satoh et al. 2012; Sun et al. 2015; Hooper und Scott 2005). Das Sonic- Hedgehog- Molekül gehört den Hedgehog $(H h)$ - Proteinen an, welche extrazelluläre Signalmoleküle sind, die während der Embryonalentwicklung vieler Organismen eine zentrale Rolle spielen (Theunissen und Sauvage 2009). Bereits bei diversen anderen Tumoren wie sowohl beim Basalzell-, Ovarial-, Prostata- und Mammakarzinom, beim klarzelligen Nierenzell- und Lungenkarzinom als auch beim Glioblastom, Medulloblastom, Rhabdomyosarkom und adamantinösen Kraniopharyngeom konnte sowohl das Tumorwachstum, als auch die Metastasenbildung durch eine aktive $H$ - Signalkaskade nachgewiesen werden (Andoniadou et al. 2012; Briscoe und Thérond 2013; Dormoy et al. 2009; Hahn et al. 1996; Hooper und Scott 2005; Kubo 2004; Lin et al. 2010; Liu et al. 2006; Low und Sauvage 2010; Wen et al. 2010) (Tabelle 1). Daher stellte sich die Frage, ob intrazelluläre Signalwege, wie zum Beispiel der Hedgehog-Signalweg, auch bei der Entstehung von Chordomen und deren Rezidiven involviert sind. Beim Nachweis einer solchen Signalkaskade wäre neben der chirurgischen Resektion und Bestrahlung eventuell ein 
chemotherapeutischer Einsatz von Hh- Inhibitoren denkbar. Hierzu wurden immunhistochemisch die Expression von Shh und Gli1 an verfügbaren Formalin- fixierten, operativ gewonnenen Präparaten von 14 kraniellen und 18 spinalen Tumorblöcken von insgesamt 14 Patienten untersucht (Kapitel 2.1). Zusätzlich wurden diese Proben mittels in situ- Hybridisierung auf eine Ptch1- und Gli1- Expression überprüft, um eine aktive Shh- Signalkaskade zu ermitteln.

\subsection{Mögliche Bedeutung der Shh-Signalkaskade bei der Entstehung von kraniellen und spinalen Chordomen}

Eine pathologische Aktivierung der Shh-Signalkaskade, bedingt durch eine Überexprimierung, Mutation oder einen Funktionsverlust der Signalmoleküle, führt zur Entstehung von Neoplasien (Tabelle 1). Teglund und Toftgård diskutieren drei verschiedene Signaltransduktionsmöglichkeiten der Beteiligung der $\mathrm{Hh}$ - Kaskade an der Tumorgenese.

Das erste (nicht kanonische) Modell beschreibt die intrinsische, Liganden (Shh)- unabhängige Weiterleitung durch Mutationen, die einen Funktionsverlust (loss of function) oder eine Überexprimierung (gain of function) und somit erhöhte Aktivität mit sich führen (Blotta et al. 2012; Teglund und Toftgård 2010). Dabei kann zum Beispiel eine geringere Ptch-Expression auf eine mögliche Ptch- Mutation oder einen Ptch- Funktionsverlust hinweisen, wie es bereits beim Basalzellkarzinom, Gorlin- Goltz- Syndrom, Medulloblastom und Rhabdomyosarkom untersucht wurde (Hahn et al. 1996; Reifenberger et al. 2005; Rudin et al. 2009; Tostar et al. 2006). Ptch kann in diesem Fall Smo nicht mehr inhibieren, und es kommt zur Aktivierung der Signalkaskade (Katoh und Katoh 2006; Omenetti et al. 2011; Wen et al. 2010).

Der zweite, kanonische Typ ist autokrin, sowie Liganden (Shh)- abhängig und geht von einer autonomen Hh- Liganden- Produktion durch die Tumorzellen aus (Blotta et al. 2012; Teglund und Toftgård 2010). Dieser Mechanismus wurde unter anderem in Glioblastomen, Melanomen, Mamma-, Prostata-, Kolon-, Pankreas-, und kleinzelligen Lungenkarzinom entdeckt (Bar et al. 2007; Berman et al. 2003; Karhadkar et al. 2004; Liu et al. 2006; Stecca et al. 2007; Varnat et al. 2009; Watkins et al. 2003). 
Beim dritten, kanonischen, parakrinen Modell exprimieren die Tumorzellen die Hh- Liganden, die den $\mathrm{H} h$ - Signalweg in den benachbarten Stromazellen aktivieren (Blotta et al. 2012). Diese wiederum regen die Tumorzellen durch einen parakrinen FeedbackMechanismus, wie zum Beispiel durch Produktion von Angiogenesefaktoren (IGF, VEGF), von Interleukin 6 und dem Wnt- Signalweg, zur weiteren Ligandenproduktion an (Justilien und Fields 2015). Ein überwiegend parakriner Weg wurde im multiplen Myelom und Lymphom nachgewiesen (Blotta et al. 2012; Dierks et al. 2007). Lungen-, Pankreas-, Ösophagus-, Colon- und Prostatakarzinome weisen sowohl den autokrinen als auch den parakrinen Weg auf (Justilien und Fields 2015). Zusammenfassend wird die Tumorprogression durch alle drei genannten Vorgänge gefördert (Gu und Xie 2015; Teglund und Toftgård 2010).

Die vorliegenden Ergebnisse dieser Studie zeigten, dass von 19 untersuchten Primärtumoren (kraniell und spinal) alle Proben für Shh (+) und 18 Proben (95 \%) für Gli1 (+) eine positive Reaktion zeigten. Auch von den elf untersuchten ersten Rezidiven (kraniell und spinal) reagierten neun (81\%) Proben Shh (+) und alle Proben Gli1 (+). Aufgrund der starken Expression von Shh und Gli1 in den Tumorzellen scheint eine Liganden (Shh)- abhängige, kanonische Aktivierung der Shh-Signalkaskade in kraniellen und spinalen Chordomen und deren Rezidiven denkbar zu sein. Ob hierfür ein auto- und/ oder parakriner Mechanismus zuständig ist, kann nicht vollständig abgeleitet werden. Bei einer potentiellen parakrinen Aktivierung korreliert die Liganden (Shh)- Expression in den Tumorzellen mit einer erhöhten Expression von Ptch1 und Gli1 in den benachbarten Stromazellen (Theunissen und Sauvage 2009), welche in dieser Versuchsreihe nicht zu erkennen war. Während der in situ- Hybridisierung wurde die Expression von Ptch1 und Gli1 lediglich im Kern der Tumorzellen, nicht in den umliegenden Stromazellen, beobachtet. Eine mögliche autokrine Aktivierung ist daher sehr naheliegend. Ein intrinsischer, Liganden (Shh)- unabhängiger Weg ist aufgrund der vorliegenden hohen Shh- Expression in den Primärtumoren und ersten Rezidiven nicht zu erwarten (Teglund und Toftgård 2010). Da auch gleichzeitig Gli1 in allen untersuchten Proben positiv war, scheint Shh als Ligand die Kaskade und somit auch die Transkription des Faktors Gli1 zu aktivieren. Ferner müsste man zum Ausschluss einer möglichen Ptch- Fehlfunktion durch gezielte DNA-Sequenzierung die Chordomproben auf bekannte Mutationen weiter untersuchen (Shendure und Ji 2008). Somit ist ein nicht kanonischer Ablauf der Hh- Signalkaskade bei Chordomen, der möglicherweise parallel zum 
klassischen Shh- Signalweg aktiv ist und mit diesem interagiert (Gu und Xie 2015; Jenkins 2009), nicht auszuschließen (Singh et al. 2011).

\subsection{Einsatz von $\mathrm{Hh}$-Signalweg- Inhibitoren in der Tumortherapie}

In den letzten Jahren wurde durch die bereits bekannte Beteiligung der $\mathrm{Hh}$ - Signalkaskade an der Tumorgenese eine besondere Priorität auf die Forschung und Erstellung von Substanzen gesetzt, die diesen Signalweg therapeutisch inhibieren können.

Für eine effektive Blockade sind mehrere Schlüsselpositionen im aktiven Ablauf denkbar (Abbildung 8). Die erste Möglichkeit ist das Unterdrücken der Bindung vom Shh- Ligand an seinen Rezeptor Ptch1. Neben dem Hh- Antikörper 5E1 ist Robotnikinin, ein synthetisch hergestelltes Molekül, für einen inhibitorischen Einfluss auf die weiterführende Signalkaskade durch extrazelluläre Bindung an Shh bekannt (Hassounah et al. 2012; Stanton et al. 2009). Es besteht ferner die Möglichkeit, den Shh- Liganden in seiner Funktion zu hemmen und somit die Bindung an den Rezeptor Ptch1 zu verhindern (Petrova et al. 2013).

Eine weitere Möglichkeit bietet die Hemmung des Smo- Proteins (Hyman et al. 2009). Sogenannte Smo- Inhibitoren, wie unter anderem Cyclopamin oder Vismodegib, werden derzeit aufgrund vielversprechender präklinischer Ergebnisse in klinischen Studien zur Bekämpfung von Medulloblastomen und Basalzellkarzinomen als Monotherapie eingesetzt (Justilien und Fields 2015; Rudin et al. 2009; Stanton und Peng 2010; von Hoff et al. 2009). Die letzte Option beläuft sich auf die Aktivitätshemmung von Gli. Das kann indirekt über Inhibition des Smo- Transports (HPI-1-4) und direkt durch Bindungsstörung von Gli an den Promotor (GANT 58, GANT 61) erfolgen (Agyeman et al. 2014; Hassounah et al. 2012; Hyman et al. 2009; Lauth und Toftgård 2007). 


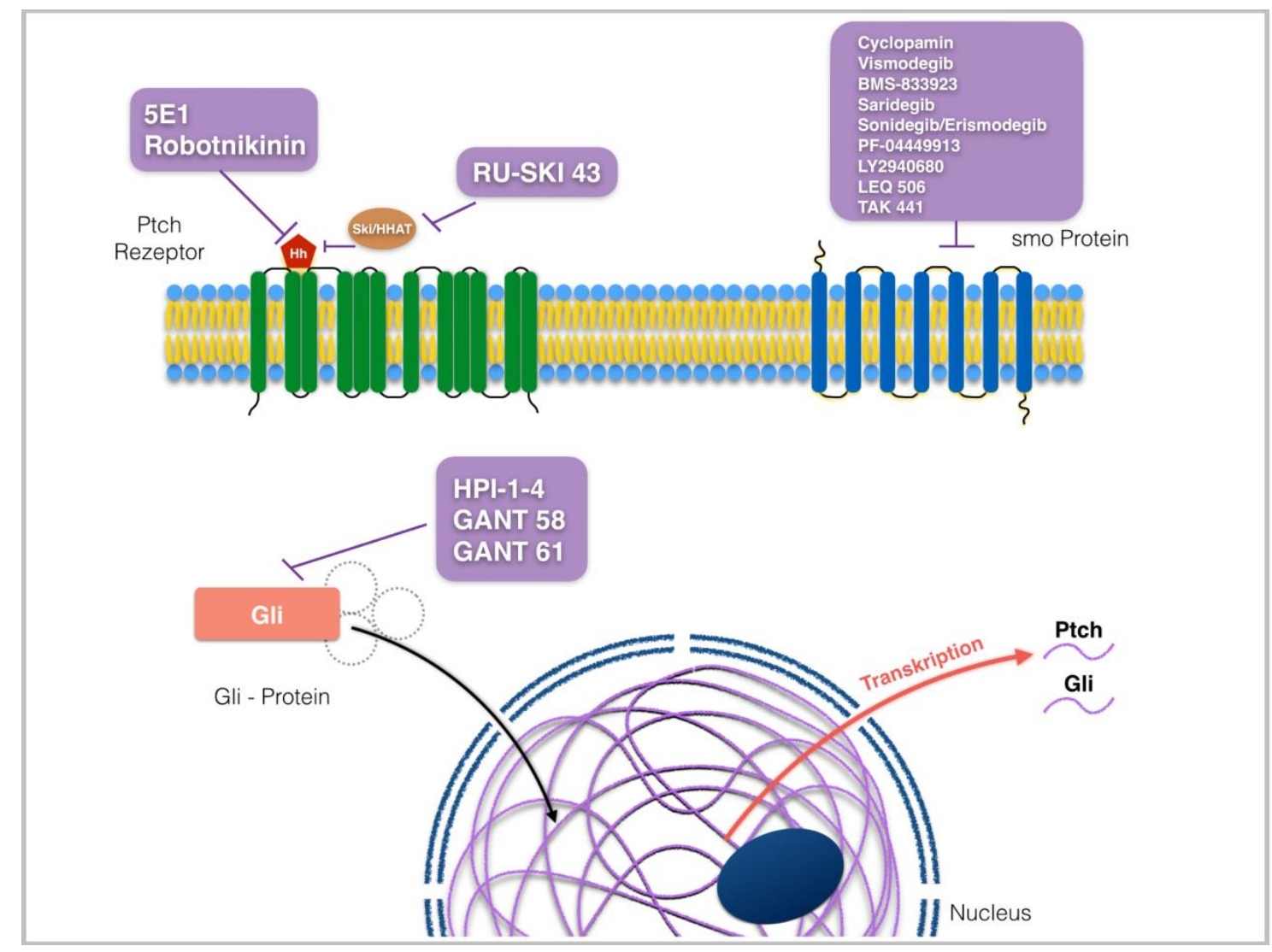

Abbildung 8: Schlüsselpositionen der Hh- Signalkaskade-Inhibitoren (modifiziert nach Justilien und Fields 2015, S. 507).

Robotnikinin und $H h$ - Antikörper $5 E 1$ inhibieren die Bindung des Liganden $H h$ an seinen Rezeptor Ptch1, während RU-SKI 43 den Hh-Ptch- Verbund durch Ski/ HHAT-Inhibition verhindert. Cyclopamin, Vismodegib und weitere Moleküle wirken inhibierend auf die Signalkaskade durch die Hemmung von Smo. Eine Aktivitätshemmung von Gli wird mittels HPI-1-4, GANT 58 und GANT 61 erreicht.

Aufgrund der hohen Shh- und Gli1- Expression in allen untersuchten Chordomproben lassen die vorliegenden Ergebnisse eine Liganden- abhängige, kanonische Aktivierung der Shh- Signalkaskade in kraniellen und spinalen Chordomen sowie deren Rezidiven vermuten (Kapitel 4.1.). Ein Unterdrücken der Bindung des Liganden Shh an Ptch1 durch 5E1, Robotnikinin oder RU-SKI 43 könnte in unseren untersuchten Chordomen somit eine Tumorprogression potentiell stoppen. Blotta et. al. diskutieren einen gleichzeitigen Einsatz von Gli- und Smo- Inhibitoren als wirkungsvollere Kombinationstherapie beim multiplen Myelom, um die $\mathrm{H} h$ - Signalkaskade an mehreren Schnittstellen zu inhibieren (Blotta et al. 2012). Basierend auf unseren Ergebnissen könnte der Einsatz von Gli- Inhibitoren wie GANT 58, GANT 61 und HPI-1-4, die direkt am Zielprotein wirken, ein weiteres Tumorwachstum der Chordome möglicherweise verhindern. Auch die indirekte Hemmung von 
Gli durch Smo-Inhibitoren könnte die aktive $H h$ - Signalkaskade möglicherweise unterbrechen und wäre genauer zu untersuchen (Agyeman et al. 2014; Gu und Xie 2015; Jenkins 2009).

\subsection{Limitationen der Arbeit}

Die Gesamtzahl von 20 untersuchten Patienten lässt keine endgültige Schlussfolgerung zu, welche durch die ausgesprochen niedrige Inzidenz der kraniellen und spinalen Chordome zu erklären ist. Da eine Vielzahl der untersuchten Tumormaterialien über einen längeren Zeitraum routinemäßig in Paraffin eingebettet worden war, konnte eine strikte RNase- freie Behandlung erst ab dem Zeitpunkt der Untersuchungen gewährleistet werden. Daher sind mögliche "falsch negative Ergebnisse“ bei der in situ- Hybridisierung denkbar.

\section{Zusammenfassung}

Die vorliegenden Ergebnisse dieser Arbeit lassen die Vermutung zu, dass die $\mathrm{Hh}$ - Signalkaskade auch bei kraniellen und spinalen Chordomen sowie deren Rezidiven eine wichtige Rolle spielt. Aufgrund der hohen Shh- und Gli1- Expression in allen untersuchten Chordomproben suggeriert die Studie eine mögliche autokrine Liganden- abhängige Aktivierung der kanonischen $\mathrm{Hh}$ - Signalkaskade. Ein nicht kanonischer, aber auch ein parakriner Mechanismus, die möglicherweise parallel ablaufen und zur Tumorprogression führen, ist aufgrund unserer Ergebnisse ebenfalls denkbar.

Eine Chemotherapie mit Hh- Inhibitoren - im Sinne von Shh-, Gli- und Smo- Inhibitoren könnte einen therapeutischen Ansatz bei vielen Chordompatienten mit mehrfachen Rezidiven darstellen. Die Durchführung einer multizentrischen Studie wäre daher sinnvoll. 


\section{Anhang}

\subsection{Patientenkollektiv und Tumormaterialübersicht}

Tabelle 9: Patientenkollektiv und Tumormaterialübersicht der Patienten mit kraniellen Chordomen ( $n=12)$. Von acht (67\%) Patienten war brauchbares Tumormaterial vorhanden (14 Tumorblöcke, davon sieben Primärtumoren, fünf erste Rezidive und zwei zweite Rezidive). Legende: ED= Erstdiagnose; J.= Jahre; Geschl.= Geschlecht; $w=$ weiblich; $m=$ männlich; PT= Primärtumor; Rez.= Rezidiv, $\mathrm{OP}=$ Operation; $\mathrm{TR}=$ Teilresektion.

\begin{tabular}{|c|c|c|c|c|c|c|c|c|c|c|c|}
\hline & $\begin{array}{l}\text { Alter } \\
\text { bei } \\
\text { ED }\end{array}$ & $\begin{array}{l}\text { Ge- } \\
\text { schl. }\end{array}$ & Lokalisation & ED & PT & $\begin{array}{c}1 . \\
\text { Rez. }\end{array}$ & $\begin{array}{l}2 . \\
\text { Rez. }\end{array}$ & 1. OP & 2. OP & 3. OP & Radiatio \\
\hline 1. & $89 \mathrm{~J}$. & w & $\begin{array}{l}\text { Fossa cranii } \\
\text { anterior }\end{array}$ & 1998 & ja & - & - & 1998 & - & - & $\begin{array}{c}- \\
\text { abgelehnt }\end{array}$ \\
\hline 2. & $38 \mathrm{~J}$. & $w$ & Clivus & 2001 & ja & ja & - & 2001 & 2001 & - & $\begin{array}{l}\text { Post } \\
\text { 2. OP }\end{array}$ \\
\hline 3. & $37 \mathrm{~J}$. & $m$ & Clivus & 1998 & ja & - & - & $\begin{array}{l}1998 \\
(T R)\end{array}$ & 1998 & - & $\begin{array}{l}\text { Post } \\
\text { 2. OP }\end{array}$ \\
\hline 4. & $25 \mathrm{~J}$. & $w$ & Clivus & 2002 & - & ja & - & $\begin{array}{c}2002 \\
\text { (alio } \\
\text { loco) }\end{array}$ & 2002 & - & $\begin{array}{l}\text { Post } \\
\text { 2. OP }\end{array}$ \\
\hline 5. & $66 \mathrm{~J}$. & w & Sella turcica & 1995 & ja & ja & - & 1995 & 2003 & - & $\begin{array}{c}- \\
\text { abgelehnt }\end{array}$ \\
\hline 6. & $10 \mathrm{~J}$. & $m$ & Clivus & 1998 & ja & - & - & $\begin{array}{l}1998 \\
\text { (TR) }\end{array}$ & 1998 & - & $\begin{array}{l}\text { Post } \\
\text { 2. OP }\end{array}$ \\
\hline 7. & $56 \mathrm{~J}$. & $\mathrm{m}$ & Clivus & 1985 & - & ja & ja & 1985 & 1988 & 1988 & $\begin{array}{l}\text { Post } \\
\text { 3. OP }\end{array}$ \\
\hline 8. & $72 \mathrm{~J}$. & $\mathrm{m}$ & Clivus & 1997 & ja & - & - & 1997 & - & - & $\begin{array}{l}\text { Post } \\
1 . \mathrm{OP}\end{array}$ \\
\hline 9. & $36 \mathrm{~J}$. & $w$ & Clivus & 1982 & ja & ja & ja & 1982 & 1984 & 1985 & $\begin{array}{l}\text { Post } \\
\text { 1. OP }\end{array}$ \\
\hline 10. & $70 \mathrm{~J}$. & $w$ & Cerebellum & 1983 & $j a$ & - & - & 1983 & - & - & $\begin{array}{l}\text { Post } \\
\text { 1. OP }\end{array}$ \\
\hline 11. & $24 \mathrm{~J}$. & $m$ & $\begin{array}{l}\text { Basis cranii } \\
\text { anterior }\end{array}$ & 1985 & ja & - & - & 1985 & - & - & $\begin{array}{l}\text { Post } \\
\text { 1. OP }\end{array}$ \\
\hline 12. & $98 \mathrm{~J}$. & $m$ & Clivus & 2003 & ja & - & - & 2003 & - & - & $\begin{array}{l}\text { Post } \\
\text { 1. OP }\end{array}$ \\
\hline
\end{tabular}


Tabelle 10: Patientenkollektiv und Tumormaterialübersicht der Patienten mit spinalen Chordomen $(n=8)$. Von sechs (75 \%) Patienten war brauchbares Tumormaterial vorhanden (18 Tumorblöcke, davon zwölf Primärtumoren und sechs erste Rezidive).

Legende: $E D=$ Erstdiagnose; J.= Jahre; Geschl.= Geschlecht; $\mathbf{w}=$ weiblich; $m=$ männlich; $P T=P r i-$ märtumor; L= Lumbal; Th= Thorakal; S= Sakral; PT= Primärtumor; Rez.= Rezidiv, OP= Operation; $T R=$ Teilresektion.

\begin{tabular}{|c|c|c|c|c|c|c|c|c|c|c|c|}
\hline & $\begin{array}{c}\text { Alter } \\
\text { bei } \\
\text { ED }\end{array}$ & $\begin{array}{l}\text { Ge- } \\
\text { schl. }\end{array}$ & Lokalisation & ED & PT & $\begin{array}{c}1 . \\
\text { Rez. }\end{array}$ & $\begin{array}{c}2 . \\
\text { Rez. }\end{array}$ & 1. OP & 2. OP & 3.OP & Radiatio \\
\hline 1. & $66 \mathrm{~J}$. & w & WS L5 & 1999 & ja & ja & - & 1999 & 2003 & - & $\begin{array}{l}\text { Post } \\
\text { 1. OP }\end{array}$ \\
\hline 2. & $18 \mathrm{~J}$. & $\mathrm{m}$ & WS (Th2/ 3) & 1990 & - & ja & - & $\begin{array}{l}1990 \\
\text { (alio } \\
\text { loco) }\end{array}$ & 1993 & - & $\begin{array}{l}\text { Post } \\
1 . \mathrm{OP}\end{array}$ \\
\hline 3. & $46 \mathrm{~J}$. & $\mathrm{m}$ & WS (S3- 5) & 1987 & ja & ja & - & 1987 & 1988 & - & $\begin{array}{l}\text { Post } \\
\text { 2. OP }\end{array}$ \\
\hline 4. & $53 \mathrm{~J}$. & w & WS (Sakral) & 2010 & ja & - & - & 2010 & - & - & $\begin{array}{l}\text { Post } \\
\text { 1. OP }\end{array}$ \\
\hline 5. & $63 \mathrm{J.}$ & $\mathrm{m}$ & WS (Sakral) & 2010 & ja & ja & - & $\begin{array}{l}2010 \\
\text { (TR) }\end{array}$ & 2010 & - & $\begin{array}{l}\text { Post } \\
\text { 2. OP }\end{array}$ \\
\hline 6. & $64 \mathrm{J.}$ & w & WS (L4) & 1992 & ja & - & - & 1992 & - & - & $\begin{array}{l}\text { Post } \\
1 . \mathrm{OP}\end{array}$ \\
\hline 7. & $80 \mathrm{J.}$ & $w$ & WS (L1/L2) & 1993 & ja & - & - & 1993 & - & - & $\begin{array}{l}\text { Post } \\
\text { 1. OP } \\
\end{array}$ \\
\hline 8. & $62 \mathrm{~J}$. & $w$ & WS (Sakral) & 1997 & - & ja & - & $\begin{array}{l}1997 \\
\text { (alio } \\
\text { loco) }\end{array}$ & 2007 & - & $\begin{array}{l}\text { Post } \\
\text { 1. OP }\end{array}$ \\
\hline
\end{tabular}

\subsection{Aktenzeichen der Ethikkommission}

Das Aktenzeichen des Ethikkommissionsvotums für dieses Studiendesign lautet 1/11/15. 
$-80^{\circ} \mathrm{C}$ Schrank

Feinwaagen

Heißluftsterilisator

Heizplatte

Hochdrucksterilisator

Hybridisierungsofen

Kamera Olympus DP71

Mikroskop Olympus BX51

pH-Meter

Reinstwassersystem

Schlittenmikrotom

Vortexer

Zentrifugen
Sanyo Sales \& Marketing GmbH, München

Sartorius AG, Göttingen

Heraeus Holding $\mathrm{GmbH}$, Hanau

Schütt Labortechnik GmbH, Göttingen

Schütt Labortechnik GmbH, Göttingen

Heraeus Holding $\mathrm{GmbH}$, Hanau

Olympus Europa $\mathrm{GmbH}$, Hamburg

Olympus Europa GmbH, Hamburg

Sartorius AG, Göttingen

Schütt Labortechnik GmbH, Göttingen

Leica Microsystems, Wetzlar

Schütt Labortechnik GmbH, Göttingen

Eppendorf AG, Hamburg

\subsection{Gebrauchswaren}

Deckgläser

Dispensionspipetten

Glaswaren

Färbekästen nach Hellendahl

Folded Filter

Objektträger

Pipettenspitzen

Röhrchen

Zellstofftupfer
Menzel GmbH \& Co. KG, Braunschweig

Eppendorf AG, Hamburg

Schott AG, Mainz

Schott AG, Mainz

GE Healthcare, Freiburg

Thermo Fisher Scientific GmbH, Schwerte

Eppendorf AG, Hamburg

Sarstedt AG \& Co, Nümbrecht

Fuhrmann $\mathrm{GmbH}$, Much 
Anti- Digoxigenin Fab fragments/ Roche Diagnostics GmbH, Mannheim, 11093274910 AP- Mix

Aquatex

Merck KgaA, Darmstadt, No. 1.08562 .0050

BBR (Boehringer Blocking Reagent) Roche Diagnostics GmbH, Mannheim, 11096176001

BCIP (5- Bromo- 4- Chloro-

Roche Diagnostics GmbH, Mannheim, 11585002001

3- Indolyl- Phospat)

$\mathrm{CaCl}_{2}+2 \mathrm{H}_{2} \mathrm{O}$

Chloroform

Citronensäure Monohydrat

Deionisiertes Formamid

Denhardt's Solution

Dextran $50 \%$

Dig RNA Labeling Mix

DMFA (Dimethylformamid)

DMPC (Dimethylpyrocarbonat)

Eisessig $100 \%$

Essigsäureanhydrid (Reagent Plus)

Ethanol

FCS (Fetal Calf Serum)

Formamid

Glycergel Mounting Medium

$\mathrm{H}_{2} \mathrm{O}_{2} 30 \%$

$\mathrm{HCl} 1 \mathrm{M}$

Immu- Mount
Fluka Chemie GmbH, Buchs, 21098

Merck KgaA, Darmstadt, No. 1.02445.100

Merck KgaA, Darmstadt, No. 1.00244.0500

Merck KgaA, Darmstadt, No. 1.09684.1000

Sigma- Aldrich Chemie GmbH, Steinheim, D2532

Sigma- Aldrich Chemie GmbH, Steinheim, D8906

Roche Diagnostics GmbH, Mannheim, 11277073910

Sigma- Aldrich Chemie GmbH, Steinheim, D4551

Sigma- Aldrich Chemie GmbH, Steinheim, D5520

Merck KgaA, Darmstadt, 1.00063.1000

Sigma- Aldrich Chemie GmbH, Steinheim, 3.201.02

Merck KgaA, Darmstadt, No. 1.000583.2500

Biochrom Ag, Berlin, Cat. No. 50015

Merck KgaA, Darmstadt, No. 1.09684.1000

Dako GmbH, Hamburg, REF C0563 LOT 10064606

AppliChem GmbH, Darmstadt, A2473, 1000

Merck KgaA, Darmstadt, 109057.1000

Shandon, Frankfurt, 198569

Lachs- Sperma DNA Natriumsalz 1 g Genaxxon biosience GmbH, Ulm, 9002-49-2

Mayers Hämalaunlösung

Merck KgaA, Darmstadt, 1.09249.0500)

$\mathrm{MgCl}_{2}$ (Magnesiumchlorid)

Natriumacetat- Trihydrat

Natriumcitrat

$\mathrm{NaCl}$ (Natriumchlorid)

Natriumhydroxid Pellets
Carl Roth GmbH, Karlsruhe, 1112180835

Merck KgaA, Darmstadt, 1.06267.1000

Merck KgaA, Darmstadt, 1.06448.1090

Merck KgaA, Darmstadt, No. 1.06404.100

Merck KgaA, Darmstadt, No. 1.06482 .1000 
Natriumlaurylsulfat

NBT (Nitrotetrazolium

Blue Chloride)

Nylonmembran

PBS (Phosphate Buffered Saline)

PFA (Paraformaldehyd)

Proteinase $\mathrm{K}$

RNase AWAY'm

Tris

Triton X- 100

Tropix I- Block

Tween 20

Xylol
Carl Roth GmbH, Karlsruhe, No. 4360.2

Sigma- Aldrich Chemie GmbH, Steinheim, 6876

Hybond- XL, Amersham, RPN 203S

AppliChem GmbH, Darmstadt, A0965, 9050

Merck KgaA, Damrstadt, 1.04005.1000

Sigma- Aldrich Chemie GmbH, Steinheim, No. P2308

Carl Roth $\mathrm{GmbH}$, Karlsruhe, A998.1

Carl Roth $\mathrm{GmbH}$, Karlsruhe, 4855.2

Carl Roth $\mathrm{GmbH}$, Karlsruhe, A.3051.2

Thermo Fisher Scientific GmbH, Schwerte, T2015

Carl Roth GmbH, Karlsruhe, No. 9127.2

Th. Geyer GmbH \& Co.KG, Renningen, No. 326.2500 
Tabelle 11: Stammlösungen

\begin{tabular}{|c|c|c|}
\hline $10 \times \mathrm{NaCl}$ & $\begin{array}{l}87,66 \mathrm{~g} \\
1000 \mathrm{ml}\end{array}$ & $\begin{array}{l}\mathrm{NaCl} \\
\text { DMPC- } \mathrm{H}_{2} \mathrm{O}\end{array}$ \\
\hline $20 \times \operatorname{SSC}(p H 7,0)$ & $\begin{array}{l}175,3 \mathrm{~g} \\
88,2 \mathrm{~g} \\
1000 \mathrm{ml}\end{array}$ & $\begin{array}{l}\mathrm{NaCl} \\
\mathrm{NaCitrat} \\
\text { Aqua dest. }\end{array}$ \\
\hline Acetatpuffer (pH 5,2) & $\begin{array}{l}300 \mathrm{ml} \\
700 \mathrm{ml}\end{array}$ & $\begin{array}{l}\text { Lösung A } \\
\text { Lösung B }\end{array}$ \\
\hline AEC- Stammlösung & $\begin{array}{l}12,5 \mathrm{~g} \\
250 \mathrm{ml}\end{array}$ & $\begin{array}{l}\text { 3- Amino-9 Ethylcarbazol } \\
\text { Dimethylformamid }\end{array}$ \\
\hline AEC- Färbelösung & $\begin{array}{l}56 \mathrm{ml} \\
4 \mathrm{ml} \\
20 \mu \mathrm{l}\end{array}$ & $\begin{array}{l}\text { Acetatpuffer pH 5,2 } \\
\text { AEC-Stammlösung } \\
30 \% \mathrm{H}_{2} \mathrm{O}_{2}\end{array}$ \\
\hline $\begin{array}{l}\text { Anti- Digoxigenin } \\
\text { Fab fragments/ AP-Mix (1:250) }\end{array}$ & $\begin{array}{l}6,5 \mu \mathrm{l} \\
1560 \mu \mathrm{l}\end{array}$ & $\begin{array}{l}\text { Anti- Digoxigenin Fab fragments/ AP } \\
\text { Block-Mix }\end{array}$ \\
\hline BBR- Puffer 0,1% (pH 7,5) & $\begin{array}{l}0,5 \mathrm{~g} \\
40 \mathrm{ml} \\
5 \mathrm{ml} \\
5 \mathrm{ml}\end{array}$ & $\begin{array}{l}\text { BBR } \\
\text { DMPC- } \mathrm{H}_{2} \mathrm{O} \\
10 \times \mathrm{NaCl} \\
\text { Tris }\end{array}$ \\
\hline BCIP & $\begin{array}{l}1 \mathrm{~g} \\
20 \mathrm{ml}\end{array}$ & $\begin{array}{l}\text { BCIP } \\
\text { DMFA } 100 \%\end{array}$ \\
\hline Block- Mix & $\begin{array}{l}1357 \mu l \\
156 \mu l \\
47 \mu l\end{array}$ & $\begin{array}{l}\text { BBR } \\
\text { FCS } \\
\text { Humanes Serum }\end{array}$ \\
\hline $\mathrm{CaCl}_{2}+2 \mathrm{H}_{2} \mathrm{O}$ & $\begin{array}{l}1,47 \mathrm{~g} \\
100 \mathrm{ml}\end{array}$ & $\begin{array}{l}\mathrm{CaCl}_{2}+2 \mathrm{H}_{2} \mathrm{O} \\
\text { DMPC- } \mathrm{H} 2 \mathrm{O}\end{array}$ \\
\hline Casein 0,2\% & $\begin{array}{l}1 \mathrm{~g} \\
500 \mathrm{ml} \\
500 \mu \mathrm{l}\end{array}$ & $\begin{array}{l}\text { Tropix I- Block } \\
\text { PBS } \\
\text { Tween } 20\end{array}$ \\
\hline Citrat pH 6,0 & $\begin{array}{l}2,1 \mathrm{~g} \\
3 \text { Pellets } \\
1000 \mathrm{ml}\end{array}$ & $\begin{array}{l}\text { Zitronensäure- Monohydrat } \\
\text { Natriumhydroxid- Pellets } \\
\text { Aqua dest. }\end{array}$ \\
\hline Dextran $50 \%$ & $\begin{array}{l}5 \mathrm{~g} \\
10 \mathrm{ml}\end{array}$ & $\begin{array}{l}\text { Dextran } \\
\text { DMPC- } \mathrm{H} 2 \mathrm{O}\end{array}$ \\
\hline DMPC- $\mathrm{H}_{2} \mathrm{O}$ & $\begin{array}{l}1 \mathrm{ml} \\
1000 \mathrm{ml}\end{array}$ & $\begin{array}{l}\text { DMPC } \\
\text { Aqua dest. }\end{array}$ \\
\hline Essigsäureanhydrid 0,5 \% & $\begin{array}{l}225 \mu \mathrm{l} \\
45 \mathrm{ml}\end{array}$ & $\begin{array}{l}\text { Essigsäureanhydrid } \\
\text { Tris-Puffer 0,1 M, pH 8,0 }\end{array}$ \\
\hline HCL 0,2 M & $\begin{array}{l}10 \mathrm{ml} \\
40 \mathrm{ml}\end{array}$ & $\begin{array}{l}\mathrm{HCL} 1 \mathrm{M} \\
\text { DMPC- } \mathrm{H}_{2} \mathrm{O}\end{array}$ \\
\hline $\begin{array}{l}\text { Hybridisierungpuffer } \\
\text { (1: } 500 \text { Sondenkonzentration) }\end{array}$ & $\begin{array}{l}2 \mathrm{ml} \\
200 \mu \mathrm{l} \\
1,8 \mathrm{ml}\end{array}$ & $\begin{array}{l}20 \times \mathrm{SSC} \\
50 \times \text { Denhardts } \\
\text { DMPC- } \mathrm{H}_{2} \mathrm{O}\end{array}$ \\
\hline
\end{tabular}




\begin{tabular}{|c|c|c|}
\hline & $\begin{array}{l}4 \mathrm{ml} \\
2 \mathrm{ml}\end{array}$ & $\begin{array}{l}\text { Formamid } \\
\text { Gelöstes Dextransulfat }\end{array}$ \\
\hline Lösung A & $\begin{array}{l}5,75 \mathrm{ml} \\
1000 \mathrm{ml}\end{array}$ & $\begin{array}{l}\text { Eisessig } \\
\text { Aqua dest. }\end{array}$ \\
\hline Lösung B & $\begin{array}{l}13,61 \mathrm{~g} \\
1000 \mathrm{ml}\end{array}$ & $\begin{array}{l}\text { Natriumacetat- Trihydrat } \\
\text { Aqua dest. }\end{array}$ \\
\hline NBT & $\begin{array}{l}75 \mathrm{mg} \\
1 \mathrm{ml}\end{array}$ & $\begin{array}{l}\text { NBT } \\
\text { DMFA } 70 \%\end{array}$ \\
\hline $\begin{array}{l}\text { NBT/ BCIP- NTM- Substratpuf- } \\
\text { fer }\end{array}$ & $\begin{array}{l}225 \mu \mathrm{l} \\
175 \mu \mathrm{l} \\
50 \mathrm{ml}\end{array}$ & $\begin{array}{l}\text { BCIP } \\
\text { NBT } \\
\text { NTM- Substratpuffer }\end{array}$ \\
\hline NTM- Substratpuffer & $\begin{array}{l}2 \mathrm{ml} \\
5 \mathrm{ml} \\
10 \mathrm{ml} \\
33 \mathrm{ml}\end{array}$ & $\begin{array}{l}\mathrm{NaCl} 5 \mathrm{M} \\
\mathrm{MgCl}_{2} 1 \mathrm{M} \\
\text { Tris } 1 \mathrm{M}, \mathrm{pH} 9,5 \\
\text { Aqua bidest. }\end{array}$ \\
\hline PBS- Puffer & $\begin{array}{l}9,6 \mathrm{~g} \\
1000 \mathrm{ml}\end{array}$ & $\begin{array}{l}\text { PBS } \\
\text { Aqua dest. }\end{array}$ \\
\hline Proteinase K- Puffer & $\begin{array}{l}800 \mu \mathrm{l} \\
357 \mu \mathrm{l} \\
34,2 \mathrm{ml}\end{array}$ & $\begin{array}{l}\mathrm{CaCl}_{2} \\
\text { Protein K- Stocklösung } \\
\text { TBS }\end{array}$ \\
\hline SDS $10 \%$ & $\begin{array}{l}10 \mathrm{~g} \\
100 \mathrm{ml}\end{array}$ & $\begin{array}{l}\text { Natriumlaurylsulfat } \\
\text { DMPC- } \mathrm{H}_{2} \mathrm{O}\end{array}$ \\
\hline Sörensenpuffer (pH 7,4) & $\begin{array}{l}1 \mathrm{l} \\
28,464 \mathrm{~g} \\
5,516 \mathrm{~g}\end{array}$ & $\begin{array}{l}\text { DMPC- } \mathrm{H}_{2} \mathrm{O} \\
\mathrm{HNa} 2 \mathrm{O} 4 \mathrm{P} \times 2 \mathrm{H}_{2} \mathrm{O} \\
\mathrm{NaH} 2 \mathrm{PO} 4 \times \mathrm{H}_{2} \mathrm{O}\end{array}$ \\
\hline TBS- Puffer & $\begin{array}{l}100 \mathrm{ml} \\
50 \mathrm{ml} \\
850 \mathrm{ml}\end{array}$ & $\begin{array}{l}10 \times \mathrm{NaCl} \\
\text { Tris } 1 \mathrm{M}, \mathrm{pH} 7,5 \\
\text { DMPC- } \mathrm{H}_{2} \mathrm{O}\end{array}$ \\
\hline TBS/ 0,1 \% Triton X- 100 & $\begin{array}{l}1 \mathrm{ml} \\
1000 \mathrm{ml}\end{array}$ & $\begin{array}{l}\text { Triton } \mathrm{X}-100 \\
\text { Aqua dest. }\end{array}$ \\
\hline TRIS- Puffer 0,1 M, pH 8,0 & $\begin{array}{l}1 \mathrm{l} \\
12,11 \mathrm{~g}\end{array}$ & $\begin{array}{l}\text { DMPC- } \mathrm{H}_{2} \mathrm{O} \\
\text { Tris/ } \mathrm{HCl}\end{array}$ \\
\hline TRIS- Puffer 1 M, pH 7,5 & $\begin{array}{l}1 \mathrm{I} \\
121,1 \mathrm{~g}\end{array}$ & $\begin{array}{l}\text { DMPC- } \mathrm{H}_{2} \mathrm{O} \\
\text { Tris/ } \mathrm{HCl}\end{array}$ \\
\hline TRIS- Puffer 1 M, pH 9,5 & $\begin{array}{l}1 \mathrm{I} \\
121,1 \mathrm{~g}\end{array}$ & $\begin{array}{l}\text { DMPC- } \mathrm{H}_{2} \mathrm{O} \\
\text { Tris/ } \mathrm{HCl}\end{array}$ \\
\hline Waschpuffer I & $\begin{array}{l}141 \mathrm{ml} \\
1,5 \mathrm{ml} \\
7,5 \mathrm{ml}\end{array}$ & $\begin{array}{l}\text { DMPC- } \mathrm{H}_{2} \mathrm{O} \\
10 \% \mathrm{SDS} \\
20 \times \mathrm{SSC}\end{array}$ \\
\hline Waschpuffer II & $\begin{array}{l}98 \mathrm{ml} \\
1 \mathrm{ml} \\
1 \mathrm{ml}\end{array}$ & $\begin{array}{l}\text { DMPC- } \mathrm{H}_{2} \mathrm{O} \\
10 \% \mathrm{SDS} \\
20 \times \mathrm{SSC}\end{array}$ \\
\hline
\end{tabular}


7. Literaturverzeichnis

Agyeman A, Jha BK, Mazumdar T, Houghton JA (2014):

Mode and specificity of binding of the small molecule GANT61 to GLI determines inhibition of GLI-DNA binding. Oncotarget $\underline{5}, 4492-4503$

al-Mefty O, Borba LA (1997):

Skull base chordomas: a management challenge. J Neurosurg $\underline{86}, 182-189$

Andoniadou CL, Gaston-Massuet C, Reddy R, Schneider RP, Blasco MA, Le Tissier P, Jacques TS, Pevny LH, Dattani MT, Martinez-Barbera JP (2012):

Identification of novel pathways involved in the pathogenesis of human adamantinomatous craniopharyngioma. Acta Neuropathol 124, 259-271

Bar EE, Chaudhry A, Lin A, Fan X, Schreck K, Matsui W, Piccirillo S, Vescovi AL, DiMeco F, Olivi A et al. (2007):

Cyclopamine-mediated hedgehog pathway inhibition depletes stem-like cancer cells in glioblastoma. Stem Cells 25, 2524-2533

Berman DM, Karhadkar S, Maitra A, Montes de Oca R, Gerstenblith, Briggs K, Parker A, Shimada Y, Eshleman, JR., Watkins D et al. (2003):

Widespread requirement for Hedgehog ligand stimulation in growth of digestive tract tumours. Nature $\underline{425}, 846-851$

Bitgood MJ, Shen L, McMahon AP (1996):

Sertoli cell signaling by Desert hedgehog regulates the male germline. Curr Biol $\underline{6}, 298$ 304

Blotta S, Jakubikova J, Calimeri T, Roccaro AM, Amodio N, Azab AK, Foresta U, Mitsiades CS, Rossi M, Todoerti K et al. (2012):

Canonical and noncanonical Hedgehog pathway in the pathogenesis of multiple myeloma. Blood 120, 5002-5013

Briscoe J, Thérond PP (2013):

The mechanisms of Hedgehog signalling and its roles in development and disease. Nat Rev Mol Cell Biol 14, 416-429

Cates JM, Itani DM, Coffin CM, Harfe BD (2010):

The sonic hedgehog pathway in chordoid tumours. Histopathology $\underline{56}, 978-979$

Chiang C, Litingtung Y, Lee E, Young KE, Corden JL, Westphal H, Beachy PA (1996):

Cyclopia and defective axial patterning in mice lacking Sonic hedgehog gene function. Nature $\underline{383}, 407-413$

Corbit KC, Aanstad P, Singla V, Norman AR, Stainier DYR, Reiter JF (2005):

Vertebrate Smoothened functions at the primary cilium. Nature 437, 1018-1021 
Di Maio S, Temkin N, Ramanathan D, Sekhar LN (2011):

Current comprehensive management of cranial base chordomas: 10-year meta-analysis of observational studies. J Neurosurg $\underline{115}, 1094-1105$

Dierks C, Grbic J, Zirlik K, Beigi R, Englund NP, Guo G, Veelken H, Engelhardt M, Mertelsmann R, Kelleher JF et al. (2007):

Essential role of stromally induced hedgehog signaling in B-cell malignancies. Nat Med $\underline{13}$, 944-951

Dormoy V, Danilin S, Lindner V, Thomas L, Rothhut S, Coquard C, Helwig J, Jacqmin D, Lang H, Massfelder T (2009):

The sonic hedgehog signaling pathway is reactivated in human renal cell carcinoma and plays orchestral role in tumor growth. Mol Cancer $\underline{8}, 123$

Fletcher C:

WHO classification of tumours of soft tissue and bone (World Health Organization classification of tumours). 4. Auflage; IARC Press, Lyon 2013

Freier K, Pungs S, Flechtenmacher C, Hofele C (2009):

Aktivierung des Sonic-hedgehog-Signalwegs in keratozystischen odontogenen Tumoren: HNO. HNO $\underline{57}, 345-350$

Freyschmidt J, Ostertag H, Jundt G, Freyschmidt-Ostertag-Jundt:

Knochentumoren mit Kiefertumoren: Klinik, Radiologie, Pathologie. 3. Auflage; Springer, Berlin 2010

Gu D, Xie J (2015):

Non-Canonical Hh Signaling in Cancer-Current Understanding and Future Directions. Cancers $\underline{7}, 1684-1698$

Hahn H, Wicking C, Zaphiropoulos PG, Gailani MR, Shanley S, Chidambaram A, Vorechovsky I, Holmberg E, Unden AB, Gillies S et al. (1996):

Mutations of the Human Homolog of Drosophila patched in the Nevoid Basal Cell Carcinoma Syndrome. Cell $\underline{85}$, 841-851

Han S, Polizzano C, Nielsen GP, Hornicek FJ, Rosenberg AE, Ramesh V (2009):

Aberrant hyperactivation of akt and Mammalian target of rapamycin complex 1 signaling in sporadic chordomas. Clin Cancer Res 15, 1940-1946

Hassounah NB, Bunch TA, McDermott KM (2012):

Molecular pathways: the role of primary cilia in cancer progression and therapeutics with a focus on Hedgehog signaling. Clin Cancer Res 18, 2429-2435 
Holtz AM, Peterson KA, Nishi Y, Morin S, Song JY, Charron F, McMahon AP, Allen BL (2013):

Essential role for ligand-dependent feedback antagonism of vertebrate hedgehog signaling by PTCH1, PTCH2 and HHIP1 during neural patterning. Development $\underline{140}$, 3423-3434 Hooper JE, Scott MP (2005):

Communicating with Hedgehogs. Nat Rev Mol Cell Biol $\underline{6}$, 306-317

Hui C, Angers S (2011):

Gli Proteins in Development and Disease. Annu Rev Cell Dev Biol 27, 513-537

Hyman JM, Firestone AJ, Heine VM, Zhao Y, Ocasio CA, Han K, Sun M, Rack PG, Sinha S, Wu JJ et al. (2009):

Small-molecule inhibitors reveal multiple strategies for Hedgehog pathway blockade. Proc Natl Acad Sci U S A $\underline{106}$, 14132-14137

Incardona JP, Gruenberg J, Roelink H (2002):

Sonic Hedgehog Induces the Segregation of Patched and Smoothened in Endosomes. Curr Biol 12, 983-995

Jenkins D (2009):

Hedgehog signalling: emerging evidence for non-canonical pathways. Cell Signal $\underline{21}$, 1023-1034

Justilien V, Fields AP (2015):

Molecular pathways: novel approaches for improved therapeutic targeting of Hedgehog signaling in cancer stem cells. Clin Cancer Res 21, 505-513

\section{Kappler R:}

Zur Rolle der Hedgehog-Signalkaskade bei der Tumorentstehung. Med. Habil. -Schr. Göttingen 2006

Karhadkar SS, Bova GS, Abdallah N, Dhara S, Gardner D, Maitra A, Isaacs JT, Berman DM, Beachy PA (2004):

Hedgehog signalling in prostate regeneration, neoplasia and metastasis. Nature $\underline{431}, 707-$ 712

Kasper M, Regl G, Frischauf A, Aberger F (2006):

GLI transcription factors: Mediators of oncogenic Hedgehog signalling. Eur J Cancer $\underline{42}$, 437-445

Katoh Y, Katoh M (2006):

Hedgehog signaling pathway and gastrointestinal stem cell signaling network (review). Int J Mol Med 18, 1019-1023 
Kim J, Kato M, Beachy PA (2009):

Gli2 trafficking links Hedgehog-dependent activation of Smoothened in the primary cilium to transcriptional activation in the nucleus. Proc Natl Acad Sci U S A 106, 21666-21671

Kozmikova I, Candiani S, Fabian P, Gurska D, Kozmik Z (2013):

Essential role of Bmp signaling and its positive feedback loop in the early cell fate evolution of chordates. Dev Biol 382, 538-554

Kubo M (2004):

Hedgehog Signaling Pathway is a New Therapeutic Target for Patients with Breast Cancer. Cancer Res $\underline{64}$, 6071-6074

Lang G:

Histotechnik: Praxislehrbuch für die biomedizinische Analytik. 2. Auflage; Springer, Wien 2013

Lauth M, Toftgård R (2007):

Non-canonical activation of GLI transcription factors: implications for targeted anti-cancer therapy. Cell Cycle $\underline{6}$, 2458-2463

Lin TL, Wang QH, Brown P, Peacock C, Merchant AA, Brennan S, Jones E, McGovern K, Watkins DN, Sakamoto KM et al. (2010):

Self-renewal of acute lymphocytic leukemia cells is limited by the Hedgehog pathway inhibitors cyclopamine and IPI-926. PloS one $\underline{5}, 15262$

Liu S, Dontu G, Mantle ID, Patel S, Ahn N, Jackson KW, Suri P, Wicha MS (2006): Hedgehog signaling and Bmi-1 regulate self-renewal of normal and malignant human mammary stem cells. Cancer Res $\underline{66}, 6063-6071$

Low JA, Sauvage FJ de (2010):

Clinical Experience With Hedgehog Pathway Inhibitors. J Clin Oncol 28, 5321-5326

Mendenhall WM, Mendenhall CM, Lewis SB, Villaret DB, Price Mendenhall N (2005):

Skull base chordoma. Head Neck 27, 159-165

Mülhardt C:

Der Experimentator: Molekularbiologie/ Genomics. 7. Auflage; Spektrum Akademischer Verlag, Heidelberg 2009

Nüsslein-Volhard C, Wieschaus E (1980):

Mutations affecting segment number and polarity in Drosophila. Nature 287, 795-801 Nybakken K, Perrimon N (2002):

Hedgehog signal transduction: recent findings. Curr Opin Gen Dev $\underline{12}, 503-511$

Ok CY, Singh RR, Vega F (2012):

Aberrant activation of the hedgehog signaling pathway in malignant hematological neoplasms. Am J Pathol $\underline{180}, 2-11$ 
Omenetti A, Choi S, Michelotti G, Diehl AM (2011):

Hedgehog signaling in the liver. J Hepatol $\underline{54}, 366-373$

Petrova E, Rios-Esteves J, Ouerfelli O, Glickman JF, Resh MD (2013):

Inhibitors of Hedgehog acyltransferase block Sonic Hedgehog signaling. Nat Chem Biol $\underline{9}$, 247-249

Ptaszyński K, Szumera-Ciećkiewicz A, Owczarek J, Mrozkowiak A, Pekul M, Barańska J, Rutkowski P (2009):

Epidermal growth factor receptor (EGFR) status in chordoma. Pol J Pathol $\underline{60}$, 81-87

Rahnama F, Toftgård R, Zaphiropoulos PG (2004):

Distinct roles of PTCH2 splice variants in Hedgehog signalling. Biochem J $\underline{378}, 325-334$

Razzaque MS, Soegiarto DW, Chang D, Long F, Lanske B (2005):

Conditional deletion of Indian hedgehog from collagen type 2alpha1-expressing cells results in abnormal endochondral bone formation. J Pathol 207, 453-461

Reifenberger J, Wolter M, Knobbe CB, Köhler B, Schönicke A, Scharwächter C, Kumar K, Blaschke B, Ruzicka T, Reifenberger G (2005):

Somatic mutations in the PTCH SMOH SUFUH and TP53 genes in sporadic basal cell carcinomas. Br J Dermatol 152, 43-51

\section{Romeis B:}

Mikroskopische Technik. 18. Auflage; Spektrum Akademischer Verlag, München, Wien 2010

Rudin CM, Hann CL, Laterra J, Yauch RL, Callahan CA, Fu L, Holcomb T, Stinson J, Gould SE, Coleman B et al. (2009):

Treatment of Medulloblastoma with Hedgehog Pathway Inhibitor GDC-0449. N Engl J Med 361, 1173-1178

Rüschoff J, Nagelmeier I, Hofmann M, Henkel T, Stoss O (2009):

Aktuelles zur ErbB2-Diagnostik beim Mammakarzinom. Pathologe 30, 147-155

Ryan KE, Chiang C (2012):

Hedgehog secretion and signal transduction in vertebrates. J Biol Chem 287, 1790517913

Satoh N, Tagawa K, Takahashi H (2012):

How was the notochord born? Evol Dev $\underline{14}, 56-75$

Schulz-Ertner D, Nikoghosyan A, Thilmann C, Haberer T, Jäkel O, Karger C, Kraft G, Wannenmacher M, Debus J (2004):

Results of carbon ion radiotherapy in 152 patients. Int J Radiat Oncol Biol Phys $\underline{58}$, 631640 
Seifert G, Donath K (1998):

Kraniale und zervikale Chordome. MKG 2, 153-159

Shah DK, Hager-Theodorides AL, Outram SV, Ross SE, Varas A, Crompton T (2004):

Reduced thymocyte development in sonic hedgehog knockout embryos. J Immunol 172 , 2296-2306

Shendure J, Ji H (2008):

Next- generation DNA sequencing. Nat Biotechnol 26, 1135-1145

Singh S, Wang Z, Liang Fei D, Black KE, Goetz JA, Tokhunts R, Giambelli C, RodriguezBlanco J, Long J, Lee E et al. (2011):

Hedgehog- producing cancer cells respond to and require autocrine Hedgehog activity. Cancer Res 71, 4454-4463

Smyth I, Narang MA, Evans T, Heimann C, Nakamura Y, Chenevix-Trench G, Pietsch T, Wicking C, Wainwright BJ (1999):

Isolation and characterization of human patched 2 ( $\mathrm{PTCH} 2)$, a putative tumour suppressor gene inbasal cell carcinoma and medulloblastoma on chromosome 1p32. Hum Mol Genet 8, 291-297

Stacchiotti S, Sommer J (2015):

Building a global consensus approach to chordoma: a position paper from the medical and patient community. Lancet Oncol $\underline{16}, 71-83$

Stanton BZ, Peng LF (2010):

Small-molecule modulators of the Sonic Hedgehog signaling pathway. Mol Biosyst $\underline{6}$, 4454

Stanton BZ, Peng LF, Maloof N, Nakai K, Wang X, Duffner JL, Taveras KM, Hyman JM, Lee SW, Koehler AN et al. (2009):

A small molecule that binds Hedgehog and blocks its signaling in human cells. Nat Chem Biol $\underline{5}, 154-156$

Stecca B, Mas C, Clement V, Zbinden M, Correa R, Piguet V, Beermann F, Ruiz i Altaba A (2007):

Melanomas require HEDGEHOG-GLI signaling regulated by interactions between GLI1 and the RAS-MEK/AKT pathways. Proc Natl Acad Sci U S A 104, 5895-5900

Steg AD, Katre AA, Bevis KS, Ziebarth A, Dobbin ZC, Shah MM, Alvarez RD, Landen CN (2012):

Smoothened Antagonists Reverse Taxane Resistance in Ovarian Cancer. Mol Cancer Ther $\underline{11}, 1587-1597$ 
Sun X, Hornicek F, Schwab JH (2015):

Chordoma: an update on the pathophysiology and molecular mechanisms. Curr Rev Musculoskelet Med, 344-352

Svärd J, Heby-Henricson K, Henricson KH, Persson-Lek M, Rozell B, Lauth M, Bergström A, Ericson J, Toftgård R, Teglund S (2006):

Genetic elimination of Suppressor of fused reveals an essential repressor function in the mammalian Hedgehog signaling pathway. Dev Cell $\underline{10}$, 187-197

Teglund S, Toftgård R (2010):

Hedgehog beyond medulloblastoma and basal cell carcinoma. Biochim Biophys Acta $\underline{1805}$, 181-208

Theunissen J, Sauvage FJ de (2009):

Paracrine Hedgehog Signaling in Cancer. Cancer Res $\underline{69}$, 6007-6010

Tostar U, Malm CJ, Meis-Kindblom JM, Kindblom L, Toftgård R, Undén AB (2006):

Deregulation of the hedgehog signalling pathway: a possible role for the PTCH and SUFU genes in human rhabdomyoma and rhabdomyosarcoma development. J Pathol 208, 1725

Tzortzidis F, Elahi F, Wright D, Natarajan SK, Sekhar LN (2006):

Patient outcome at long-term follow-up after aggressive microsurgical resection of cranial base chordomas. Neurosurgery $\underline{59}, 230-237$

Varjosalo M, Li S, Taipale J (2006):

Divergence of hedgehog signal transduction mechanism between Drosophila and mammals. Dev Cell 10, 177-186

Varnat F, Duquet A, Malerba M, Zbinden M, Mas C, Gervaz P, Ruiz i Altaba A (2009): Human colon cancer epithelial cells harbour active HEDGEHOG-GLI signalling that is essential for tumour growth, recurrence, metastasis and stem cell survival and expansion. EMBO Mol Med 1, 338-351

von Hoff DD, LoRusso PM, Rudin CM, Reddy JC, Yauch RL, Tibes R, Weiss GJ, Borad MJ, Hann CL, Brahmer JR et al. (2009):

Inhibition of the Hedgehog Pathway in Advanced Basal-Cell Carcinoma. N Engl J Med $\underline{61}$, 1164-1172

Wacker A, Stadler P, Pless M (2002):

Chordome - diagnostische Schritte und therapeutische Konsequenzen. Dtsch med Wochenschr $\underline{127}, 1774$

Walcott BP, Nahed BV, Mohyeldin A, Coumans J, Kahle KT, Ferreira MJ (2012):

Chordoma: current concepts, management, and future directions. Lancet Oncol $\underline{13}, 69-76$ 
Watkins DN, Berman DM, Burkholder SG, Wang B, Beachy PA, Baylin SB (2003):

Hedgehog signalling within airway epithelial progenitors and in small-cell lung cancer.

Nature $\underline{422}, 313-317$

Wen X, Lai CK, Evangelista M, Hongo J, Sauvage FJ de, Scales SJ (2010):

Kinetics of hedgehog-dependent full-length Gli3 accumulation in primary cilia and subsequent degradation. Mol Cell Biol 30, 1910-1922

Yang L, Xie G, Fan Q, Xie J (2010):

Activation of the hedgehog-signaling pathway in human cancer and the clinical implications. Oncogene $\underline{29}$, 469-481 


\section{Danksagung:}

Mein besonderer Dank gilt Herrn Prof. Dr. med. Veit Rohde, Klinik für Neurochirurgie, für die Überlassung des Themas und Herrn PD Dr. med. Reza Akhavan-Sigari, Klinik für Neurochirurgie, für die fachliche, umfangreiche und hilfsbereite Betreuung und für die Gespräche und Anregungen während des gesamten Zeitraums.

Herrn PD Dr. med. Walter Schulz-Schaeffer, Institut für Neuropathologie, danke ich für seine wissenschaftliche Unterstützung, das Ermöglichen der Laborversuche und das entgegenbrachte Interesse an meiner Arbeit. Zudem danke ich Herrn Dr. med. Arne Wrede für die hilfsbereite Unterstützung.

Des Weiteren danke ich Frau Prof. Dr. med. Heidi Hahn, Frau Dr. rer. nat. Frauke Nitzki und Frau Dr. rer. nat. Penelope Pelczar für die hilfsbereite, fachliche Unterstützung und für die Bereitstellung der in situ- Hybridisierungssonden.

Ein weiterer großer Dank gilt Frau Manuela Becker, Frau Tatjana Pfander, Frau Kerstin Brekerbohm, Frau Katja Schulz und Frau Kerstin Lorentsen für die gute Zusammenarbeit, gründliche Einarbeitung in alle Labortätigkeiten und guten Ratschläge. 